\title{
Working
}

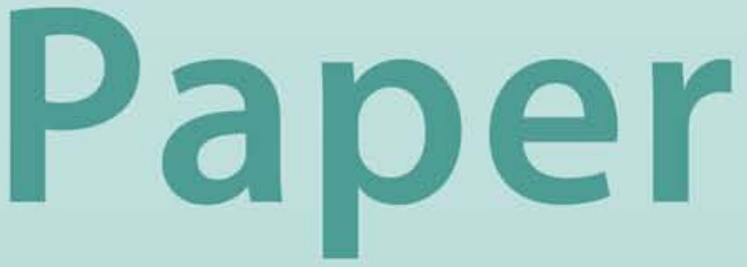


Helping Hand or Grabbing Hand? Supervisory Architecture, Financial Structure and Market View

Donato Masciandaro and Marc Quintyn 


\title{
IMF Working Paper
}

\author{
IMF Institute
}

\section{Helping Hand or Grabbing Hand? Supervisory Architecture, Financial Structure and Market View}

\section{Prepared by Donato Masciandaro and Marc Quintyn ${ }^{1}$}

Authorized for distribution by Andrew Feltenstein

February 2008

\begin{abstract}

\section{This Working Paper should not be reported as representing the views of the IMF.}

The views expressed in this Working Paper are those of the author(s) and do not necessarily represent those of the IMF or IMF policy. Working Papers describe research in progress by the author(s) and are published to elicit comments and to further debate.

The literature stresses the importance of financial market characteristics in determining the supervisory architectures. In the real world it is not always clear to what extent market features are taken into account. We present two complementary approaches to gain insights in the above relationship. First, an empirical test of two theories - the helping and the grabbing hand view of government-seems more consistent with the latter, presuming the market demonstrates a preference for consolidation of supervisory powers. Second, a survey among financial CEOs in Italy confirms a preference for a consolidated supervisory regime and reveals only weak consistency between the views of the policymakers and the market operators.

JEL Classification Numbers: G18, G28, E58

Keywords: Financial supervision, political economy, grabbing hand, banking concentration

Author’s E-Mail Address: donato.masciandaro@unibocconi.it; mquintyn@imf.org

\footnotetext{
${ }^{1}$ Donato Masciandaro is full professor, Paulo Baffi Centre, Bocconi University, Milan, Italy. An earlier version of this paper was presented at the "Second European Conference on Financial Regulation and Supervision-Finance, Law and Data” June 18-19, 2007 at Bocconi University, Milan. The authors would like to thank Michael Taylor, and comments. All remaining errors are the authors'.
} Martin Čihák, Burkhard Drees and Caryl McNeilly, as well as participants at the Conference for useful suggestions
\end{abstract}


I. Introduction

II. Do Markets Matter in Designing Financial Supervision Architectures? Helping Hand View versus Grabbing Hand View

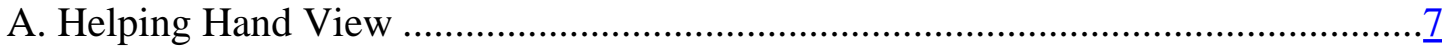

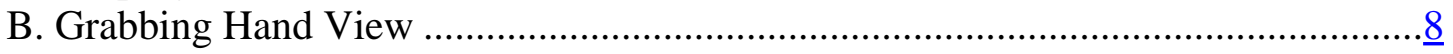

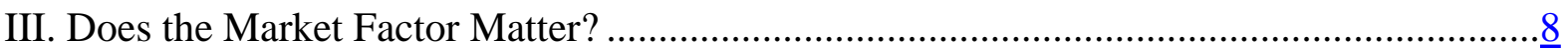

A. Basic Model and Earlier Results .................................................................... 10

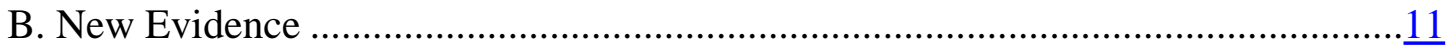

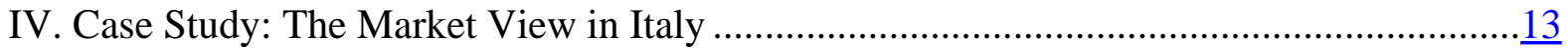

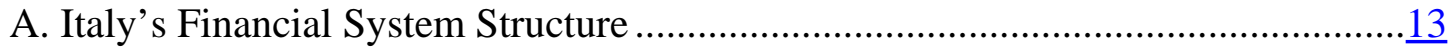

B. Supervisory Framework ...................................................................

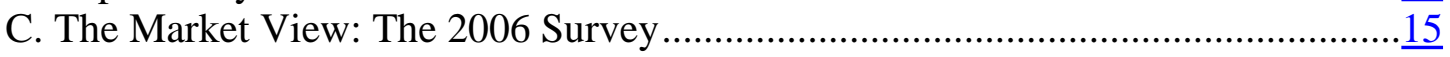

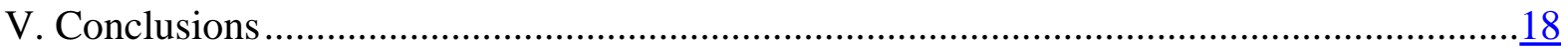

Tables

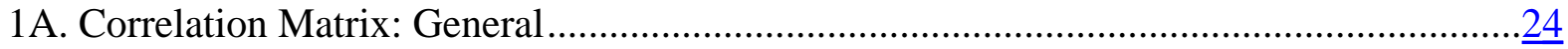

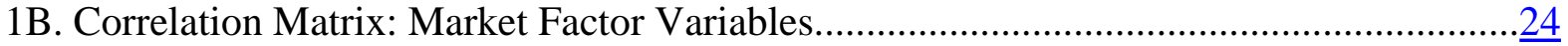

1C. Summary Statistics: Market Factor Variables............................................................24

2. Ordered Logit Estimates with the Basic Model ............................................................. $\frac{25}{26}$

3. Ordered Probit Estimates with the Basic Model............................................................26

4. Ordered Logit Estimates with the Basic Model and the New Data ...................................27

5. Ordered Probit Estimates with the Basic Model and New Data ......................................28

6. Ordered Logit Estimates with the Bandwagon Effect .....................................................29

7. Ordered Probit Estimates with the Bandwagon Effect ................................................. $\frac{30}{31}$

8. Ordered Logit Estimates with the Conglomeration Effect .............................................31

9. Ordered Probit Estimates with the Conglomeration Effect ...............................................32

10. Ordered Logit Estimates with the Concentration Effect...............................................33

11. Ordered Probit Estimates with Concentration Effect...................................................34

Figures

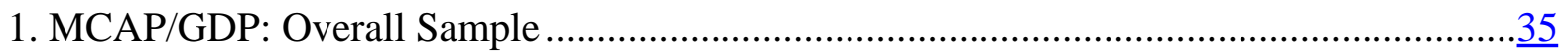

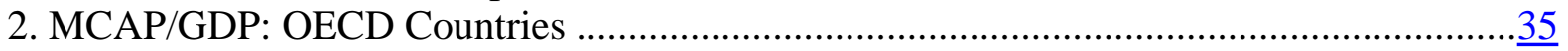

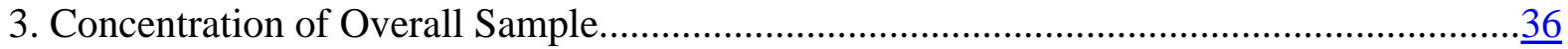

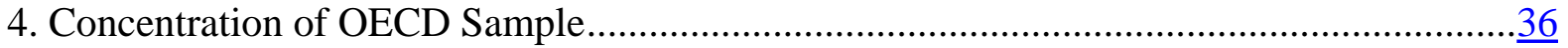

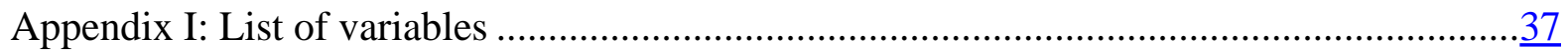

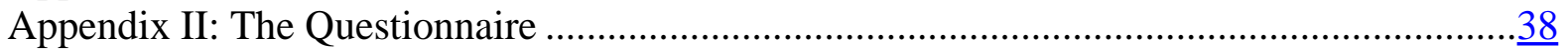

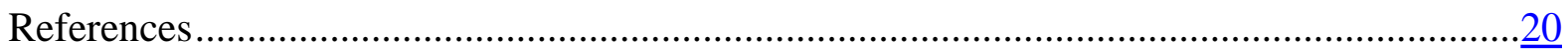




\section{INTRODUCTION}

In recent years many countries have made drastic changes to the architecture of financial supervision, and more countries are contemplating modifications. The current restructuring wave is making the supervisory landscape less uniform than in the past. In several countries the architecture still reflects the classic model, with separate agencies for banking, securities and insurance supervision. However, an increasing number of countries show a trend towards consolidation of supervisory powers, which in some cases has culminated in the establishment of a unified regulator, either inside or outside the central bank. ${ }^{2}$

These changes in the supervisory architecture are taking place against the backdrop of fundamental changes in the financial markets. The financial industry is changing its conventional face, with a blurring of the traditional boundaries between banking, securities and insurance, and the formation of large conglomerates. The natural question that follows from a confrontation of these trends is: in a given country, is there any relationship between the shape of the supervisory architecture and the evolving features of its financial industry?

As a matter of fact, the authorities in the first eye-catching examples of this trend-the United Kingdom and Australia - explicitly justified the supervisory reorganization by referring to the changes in their financial industries along the lines indicated above. ${ }^{3}$ In other cases, such as South Africa, supervisory unification was seen as premature because the authorities did not see any clear trends of blurring of boundaries, or formation of conglomerates. Hence it was decided that bank supervision would remain with the Reserve Bank of South Africa and that supervision of all other subsectors would be unified in another, new agency (Bezuidenhout, 2004).

This last example notwithstanding (and there are a few more), there has been a tendency in recent years among policy makers to allude to developments in their financial markets to justify a consolidation of supervisory powers. More generally, the idea that supervisory consolidation and unification is (in part) in response to the blurring and conglomeration trends in the financial sector has become common place in overview studies devoted to the recent evolution in supervisory design. ${ }^{4}$

However, against this widespread "belief" stands the finding that there is a general lack of theoretical underpinning and empirical evidence to corroborate the view that the structure of the financial markets plays a decisive role in shaping a country's supervisory structure. The only empirical paper on the topic, Masciandaro (2006), finds that when policymakers choose the supervision model, they actually seem to neglect some specific features of their financial markets (market capitalization, bank based versus market based setting). So the question

\footnotetext{
${ }^{2}$ For surveys of recent developments see, among others, De Luna Martinez (2003), Masciandaro (2005), and Čihák and Podpiera (2007).

${ }^{3}$ See among others, for the U.K. Briault (1999) and Davis (2004), and for Australia, Commonwealth of Australia (1996). Years before the current wave of supervisory restructuring started, the Nordic countries (Denmark, Norway and Sweden) had already established a unified supervisor. The high degree of concentration of their financial systems was mentioned as a main reason for this reform (see Taylor and Fleming ,1999).

${ }^{4}$ See, for example, Taylor and Fleming (1999) and the case studies collected in Masciandaro (2005b) and Masciandaro and Quintyn (2007).
} 
regarding the importance of market features for the design of the supervisory structure remains broadly unanswered and this paper will explore the empirical linkages further.

A second, related and equally relevant question in this debate, concerns the views of the supervised entities themselves on the supervisory architecture, and the extent to which these views are taken into account in the decision making process. Systematic and empirical evidence in this domain too is rather scarce. Westrup (2007) is one of the few sources on the topic. He reports for instance that in Germany, at least one part of the financial sector representatives (represented in the Bunderverband Deutscher Banken, BdB) were in favor of a unified model outside the Bundesbank, and with a weaker degree of independence from the government than the Bundesbank. This is one of the clearest examples of views expressed by the market at the time of a reform. Moreover, these views seem to have had an impact on the final decision. For the United Kingdom, in contrast, his research finds no evidence of explicit views expressed by the market actors at the time of the reforms. The Wallis Commission in Australia reports prior consultation with the financial sector on the reforms of the supervisory framework (Commonwealth of Australia, 1996). Beyond this, almost anecdotal, evidence we have little information on views from the market, and on their potential impact on the decision making process in individual countries.

This paper offers two complementary contributions to the debate about the importance of the "market factor" in reshaping supervisory architectures. By "market factor" we understand hereafter the two elements referred to above: the structure of the markets and the views of the market participants (financial institutions). In the first part of the paper we take a politicaleconomy view to explore the impact of market structure on the supervisory architecture. Since a purely economic view-represented in the selection of the "banks-versus-market" variable in Masciandaro (2006) — does not seem to yield clear results, we explore this issue from a political-economic point of view. From a theoretical point of view, at least two alternative theories can be formulated to explain the relationship between the structure of the markets and the supervisory architecture-the helping hand view (HHV) of government and the grabbing hand view (GHV). ${ }^{5}$ The premise common to both is that policymakers are politicians: politicians are held accountable at the elections for how they have pleased the voters. All politicians are motivated by the goal of pleasing the voters in order to win the elections. The main difference between the two theories concerns which voters they wish to please in the first place.

Under HHV, the policymaker's choices are motivated by improving general welfare. Therefore, it is possible to claim that their efforts to reform the supervisory structure aim at improving the efficiency of overall resource allocation, and that the market features are an important factor to be taken into consideration. According to the GHV approach, the policymakers are motivated by the goal of pleasing the interest of specific, well-defined voters. In our case, the financial industry may be considered a highly organized and powerful interest group. The financial industry is likely to be a smaller and more coherent group than the consumers of their services, and therefore politically better organised. The policymaker, in defining the supervisory setting, is likely to be influenced by the market view of supervision, if this increases the probability of

\footnotetext{
${ }^{5}$ The helping hand view goes back to Pigou (1938) and the grabbing hand view was first elaborated by Shleifer and Vishny (1998).
} 
his/her re-election. Therefore, the market view becomes the crucial variable in determining the shape of the supervisory regime under the grabbing hand approach.

The second part of the paper starts from the view that the opinion of the market participants regarding the supervisory architecture is also an important aspect to study. Understanding the market preferences can be useful to predict either the effectiveness and/or the likelihood of a supervisory regime. Again, this issue has not been addressed systematically in the literature. So here we present and analyze the results of a survey among CEOs of Italian financial institutions, about their preferences and beliefs on supervisory structure and regulatory governance and their views on the political decision-making process.

This paper is structured as follows. Section II discusses the background to our analysis in the context of the HHV versus GHV hypotheses, and Section III reports on our empirical tests. In Section IV we discuss the survey on market views. Section V brings the main conclusions together.

\section{Do MARKets Matter in Designing FinANCial Supervision Architectures? HELPING HAND ViEW VERSUS GRABBING HAND ViEW}

Do the features of financial markets matter when authorities determine the shape of the supervisory architecture? The relevance of this question is of a recent date. Until roughly 15 years ago, the issue of supervisory architecture was considered irrelevant. First of all, the fact that only banking systems were considered needing supervision made several of the current organizational questions meaningless. In such a context, the supervisory design was either considered deterministic (i.e., it is an exogenous variable), or accidental (i.e., it is a completely random variable). ${ }^{6}$

The situation has changed. The changes in the financial markets, resulting in the growing systemic importance of insurance, securities and pension fund sectors have made supervision of all segments of the financial system important, and raise the issue as to whether the newly emerging financial supervisory structures are endogenous, i.e., designed in response to these developments and other factors.

The starting point for answering the above question is based on three crucial hypotheses. First of all, we claim that policy makers base their decisions whether to reform the supervisory regime or not on the expected gains and losses of different supervisory models. ${ }^{7,8}$ Second, the expectations of policymakers, whatever their own specific goals are, will likely be influenced by structural variables - such as the features of the financial markets - that may vary from country to country. We test the hypothesis that in every country, given the structural endowment, these

\footnotetext{
${ }^{6}$ For an historical perspective, see the discussion in Goodhart (2007) and Capie (2007).

${ }^{7}$ For an analysis of pros and cons of alternative models of supervision see, among others, Arnone and Gambini (2007), Čihák and Podpiera (2007), Di Giorgio and Di Noia (2007).

${ }^{8}$ The importance of the policymakers' preferences in explaining how supervisory settings come about can be tackled in different ways. For example, the political economy of financial regulation can be analyzed as the outcomes of conflicts which are linked to inclusive and exclusive processes. See Mooslechner et al. (2006) and in particular Lutz (2006).
} 
variables can determine, ceteris paribus, the gains or losses policymakers expect from a specific supervisory regime. The supervisory regime is the dependent variable. Finally, economic agents have no information on the true preferences of the policymaker: the latter's optimal degree of financial supervision concentration is a hidden variable. ${ }^{9}$

The crucial element in considering the policymaker's objective as a factor in the design of the supervisory architecture is the identification of his/her preferences. The first approach to identifying the policymaker's function could be the so-called narrative approach, in which official documents are interpreted to gauge the choices of policymakers. ${ }^{10}$ One drawback of this approach is that there exist often substantial differences between the pronouncements of policymakers and their actual preferences.

The second approach, which we intend to follow here, is to consider the actual choices of policymakers in determining the level of financial supervision concentration (factual approach). At each random point in time, we observe the policymaker's decision to maintain or reform the financial supervision architecture. In other words, we consider that policymakers are faced with discrete choices. According to the factual approach, we can investigate if the features of the financial markets play any role in determining the actual shape of the supervisory architecture. We can explore two alternative views - the helping hand view of government (HHV) and the grabbing hand view (GHV) — which share a common premise: the policymakers are politicians, i.e., they are "career concerned" agents, motivated by the goal of pleasing the voters in order to win the elections. The main difference concerns which voters-general interest versus vested interest- they are trying to please.

Thus, although we agree with most scholars that the institutional structure of financial sector supervision is a second order issue, and that the governance of these institutions, the quality of rules and regulations and of the supervisory process are much more important, this paper contends that the institutional structure is not unimportant either. An appropriate structure can foster efficient and effective supervision. By taking a political economy view, we can test the hypothesis that politicians may wish to use reform (or status quo) to gain or keep influence into the supervisory process, and through it, into the operation of the financial system. ${ }^{11}$ Hence, institutional reform can be used by politicians to influence the quality of the regulatory and supervisory process.

\footnotetext{
${ }^{9}$ By financial supervision concentration we refer to the degree of integration or consolidation of the supervisory function. At one end of the spectrum are those countries that have several sector-specific supervisory agencies; at the other end are the countries that have established a unified supervisor.

${ }^{10}$ The narrative approach has been used in, for instance, Westrup (2007).

${ }^{11}$ For instance, a majority of commentators agrees that the government's decision to establish a unified regulator in Poland in 2006 was mainly meant to curb the central bank's power and to regain some government influence over financial sector developments. See for instance remarks and citations in Dow Jones Commodities Service (September 14, 2006), Agence France Press (September 29, 2006), and Associated Press Newswires (October 3 , 2006).
} 


\section{A. Helping Hand View}

In general, the HHV government, i.e., one that aims to maximize social welfare, wishes to correct or prevent market imperfections. ${ }^{12,13}$ In the case of designing the financial supervision regime, the $\mathrm{HHV}$ policymaker can choose to maintain or reform the degree of supervisory concentration in order to improve the overall efficiency in resource allocation, and therefore he/she has to take into account the structure of the financial system.

The crucial stylized fact in this regard is the blurring of boundaries in the financial industry which is leading to an increasing integration of the banking, securities and insurance markets, as well as their respective products and instruments. The blurring effect has caused two interdependent phenomena: (i) the emergence of financial conglomerates, which is likely to produce important changes in the nature and dimensions of the individual intermediaries, as well as in the degree of unification of the banking and financial industry; and (ii) a growing securitization of the traditional forms of banking activity and the proliferation of sophisticated ways of bundling, repackaging and trading risks, which weakens the classic distinction between equity and debt, and is bringing changes in the nature and dimensions of the financial markets.

The HHV policymaker recognizes that the supervisory architecture was created for a structure of the financial system that is no longer consistent with these structural changes. The supervisory boundaries no longer reflect the actual features of the financial industry. The question of the institutional setting of supervision becomes a policy issues. In particular, the HHV policymaker wonders if a unification in supervision has to follow the blurring trends in the markets. In other words, should supervisory activities be integrated, through the establishment of a single financial regulator? In general, the HHV policymaker will find advantages and disadvantages in the establishment of a unified financial sector supervisor. ${ }^{14}$

Potential benefits of unification include a more efficient and effective control of financial conglomerates and financial markets in a state of flux. By providing more effective supervision the HHV policymaker would please the financial consumers-i.e., the citizens - by contributing to the existence of a stable financial environment. Most likely this would increase the probability to win the election.

The views expressed by the market participants on the optimal structure of supervision could become an important factor in the discussion on improving efficiency and effectiveness of financial supervision. From the point of view of the market participants a unified supervisor could solve problems of duplication, overlap and inconsistency in controls and reporting requirements, and regulatory gaps. It could also increase the possibility of having a level playing field, characterized by competitive neutrality. In other words a unified supervision could mean a decrease in the expected compliance costs. If the market participants like more

\footnotetext{
${ }^{12}$ Pigou (1938).

${ }^{13}$ Although the HHVwas identified by Pigou as the government's way to address market imperfections and enhance social welfare, it has been pointed out that this view of the government can also lead to excesses. Barth, Caprio, and Levine (2004) point out that theHHV can stimulate the introduction of regulations that in fact choke financial sector development, such as entry restrictions and limits on activities.

${ }^{14}$ Abrams and Taylor (2002), Arnone and Gambini (2007), Čihák and Podpiera (2007).
} 
concentrated supervision, a closer alignment between general interest (effective supervision) and specific (market participants) interest (efficient supervision) is more likely to occur. Therefore, the HHV policymaker can be sensitive to the market view.

\section{B. Grabbing Hand View}

The GHV policymaker is also an elected politician who has to please the voters. But now we consider the case of lobbies, that can influence the policymaker's choices. In contrast with the HHV policymaker, the GHV government would tend to give benefits only to a small but well organized interest group. The GHV policymaker is captured by a specific interest group, whose support is considered fundamental for (re)election. ${ }^{15}$ We can suppose ${ }^{16}$ that, while the common voters can influence the policymaker only through elections, the vested interest group can influence the policymaker through explicit or implicit contributions, important enough to increase the chances of winning the elections. In this case the preferences of the interested group would become the fundamental variable in explaining the policy choices.

Faced with the issue of (re)shaping the architecture of financial supervision, the GHV policymaker can be influenced by the market features, but-more importantly-he/she will most likely be sensitive to the preferences of the market participants. The demand by the financial industry for more consolidated supervision can be a disguised form of capture. Capture is more likely to occur: (i) the greater the level of concentration in the financial industry is; and (ii) the more the number of supervisory authorities decreases. In these circumstances, if premises (i) and (ii) together hold, the establishment of a single financial authority can become an institutional deficiency from a social welfare point of view, and undermine effectiveness and efficiency of supervision.

\section{DOES THE MARKeT FACTOR MATTER?}

To assess empirically the role of the market structure in determining the degree of concentration in the financial supervision architecture from the perspective of these two alternative views, we estimate a model of the probability of different regime decisions as a function of a set of exogenous structural variables. To that effect, we use the approach adopted by Masciandaro (2005a) and (2006). Weaving a cross country perspective into an empirical analysis consistent with this discrete choice process involves claiming the existence of unobservable policymaker utilities $U i j$, where each $U i j$ is the utility received by the ith national policymaker from the $j t h$ level of supervision consolidation. Since the utility Uij is unobservable, we represent it as a random quantity, assuming that it is composed of a systematic part $U$ and a random error term $\varepsilon$. Furthermore, we claim that the utilities $U i j$ are a function of the attributes of the alternative institutional level of supervision consolidation and the structural characteristics of the policymaker's country.

\footnotetext{
${ }^{15}$ We use the terminology of the regulatory capture theory-Stigler 1971 — to describe a situation where both policymaker and industry pursue their own benefits, rather than social welfare.

${ }^{16}$ As in Alesina and Tabellini (2004).
} 
By combining the two hypotheses, we have a random utility framework for the unobservable supervision consolidation variable. As usual, we assume that the errors $\varepsilon i j$ are independent for each national policymaker and institutional alternative, and normally distributed. The independence assumption implies that the utility derived by one national policymaker is not related to the utility derived by a policymaker in any another country, and that the utility that a policymaker derives from the choice of a given level of financial consolidation is not related to the utility provided by the other alternative.

Therefore, supervisory regimes can be viewed as resulting from an unobserved variable: the optimal degree of financial supervision consolidation, consistent with the policymaker's utility. Each regime corresponds to a specific range of the optimal financial supervision consolidation, with higher discrete values of a given index corresponding to a higher range of financial unification values. We use the Index of Financial Authorities Concentration (FAC) proposed in Masciandaro (2004). Since the FAC Index is a qualitative ordinal variable, the estimation of a model for such a dependent variable necessitates the use of a specific technique. Our qualitative dependent variable can be classified into more than two categories, given that the FAC Index is a multinomial variable. But the FAC Index is also an ordinal variable, given that it reflects a ranking. Then the ordered model is an appropriate estimator, given the ordered nature of the policymaker's alternative.

Let $y$ be the policymaker's ordered choices taking on the values $(0,1,2, \ldots, 7)$. The ordered model for $y$, conditional on a set of $K$ explanatory variables $x$, can be derived from a latent variable model. In order to test this relationship, let us assume that the unobserved variable, the optimal degree of financial supervision consolidation $y^{*}$, is determined by:

$$
y^{*}=\beta^{\prime} x+\varepsilon
$$

where $\varepsilon$ is a random disturbance uncorrelated with the regressors, and $\beta$ is a $1 \mathrm{x} K$ regressors' vector.

The latent variable $y^{*}$ is unobserved. What is observed is the choice of each national policymaker to maintain or to reform the financial supervisory architecture. This choice is summarized in the value of the FAC Index, which represents the threshold value. For the dependent variable we have seven threshold values. Estimation proceeds by maximum likelihood, assuming that $\varepsilon$ is normally distributed across country observations, and the mean and variance of $\varepsilon$ are normalized to zero and one. This model can be estimated with an ordered Logit model or with an ordered Probit model. ${ }^{17}$

On the basis of this framework, we can analyze the role of the market features in the determination of the supervisory architecture. In spite of the contrast between the HHV and

\footnotetext{
${ }^{17}$ The Logit model differs from the Probit model only in the cumulative distribution function used to define choice probabilities. The maximum likelihood estimations were carried out by a packaged-ordered Probit and ordered Logit commands in STATA. We present both the Logit and Probit results, given that, as usual, there is little basis for choosing between both models.
} 
GHV views, they remain difficult to disentangle from an empirical point of view, among others because it is not easy to find empirical variables that consistently and unambiguously represent each of these two approaches.

\section{A. Basic Model and Earlier Results}

We start from the model developed in Masciandaro (2005a) and (2006). The model identified six potential determinants of the financial supervision regime. ${ }^{18}$ First, the probability that a country will move toward a more concentrated form of supervision can depend on the overall size of the country (GDP, economic factor, proxied by GDP per capita). Second, the choice of the policymaker regarding the degree of supervisory concentration seems to be related to the role played by the central bank in the supervisory process (CBFA, central bank factor, based on an index of central bank involvement in the supervisory process). ${ }^{19}$ Third, the quality of the political environment could be important in determining the policymaker's choice (political factor, GGOV), as well as the legal system (legal factor, LEN for common law, LFR for civil code traditions, and LGS for German-Scandinavian legal traditions), and the geographical location (geographical factor, measured by latitude, LAT, i.e., distance from the equator). Finally, the policymaker can choose to maintain or change the degree of supervisory unification in response to the structure of the financial system (market factor, MvB which indicates whether a financial system is bank-based or market-based). In addition, the model includes a measure of stock market capitalization (MCAP) to indicated the size of the securities markets. The equation also includes dummies for whether the countries belongs to OECD and/or EU.

To test the potential determinants of financial supervision architectures, the following general specification is adopted: ${ }^{20}$

$$
\begin{aligned}
(F A C)_{\mathrm{i}} & =\beta_{0}+\beta_{1}(C B F A)_{\mathrm{i}}+\beta_{2}(\mathrm{GDP})_{\mathrm{i}} \\
& +\beta_{3}(\text { OECD })_{\mathrm{i}}+\beta_{4}(\mathrm{MVB})_{\mathrm{i}}+\beta_{5}(\mathrm{MCAP})+\beta_{6}(\mathrm{GGOV}) \\
& +\beta_{7}(E U)+\beta_{8}(L A T)+\beta_{9}(L E N)+\beta_{10}(\mathrm{LFR})+\beta_{11}(L G S)+\varepsilon_{t}
\end{aligned}
$$

with country ${ }^{21} i=1 \ldots 88$.

\footnotetext{
${ }^{18}$ For the data sources, see Appendix I.

${ }^{19}$ Masciandaro (2005a): for each country, and given the three traditional financial sectors (banking, securities and insurance), the CBFA index is equal to: 1 if the central bank is not assigned the main responsibility for banking supervision; 2 if the central bank has the main (or sole) responsibility for banking supervision; 3 if the central bank has responsibility in any two sectors; 4 if the central bank has responsibility in all three sectors. In evaluating the role of the central bank in banking supervision, we considered the fact that, whatever the supervision regime, the monetary authority has responsibility in pursuing macro financial stability. Therefore, we chose the relative role of the central bank as a rule of thumb: we assigned a greater value (2 instead of 1 ) if the central bank is the sole or principal institution responsible for banking supervision.

${ }^{20}$ The correlation matrix for the variables is in Table $1 \mathrm{~A}$.

${ }^{21}$ The country sample depends on the availability of institutional data. Given the 267 world countries (UN members are 180), our 89 countries represent 60 percent of world GDP and 82 percent of the world population.
} 
Tables 2 and 3 show the Logit and Probit estimates of Equation (2). In the multinomial ordered models the impact of a change in an explanatory variable on the estimated probabilities of the highest and lowest of the order classifications - in our case the Single Authority model (unified supervisor) and the "pure” Multi-Sector supervisory model—is unequivocal: If $\beta_{j}$ is positive, for example, an increase in the value of $x_{j}$ increases the probability of having the Single Authority model, while it decreases the probability of having the "pure” Multi-supervisory model.

The results of the estimates show that the probability that a country will move toward a Single Authority model is higher: (i) the smaller the size of the economy; ${ }^{22}$ (ii) the lesser the central bank is involved in supervision before the reform; and (iii) when the jurisdiction operates under the Civil Law - particularly if the legal framework is characterized by German and Scandinavian roots. The market factor does not seem to matter in this specification.

\section{B. New Evidence}

To further the analysis of the role of the market factor this section tests three innovations to the basic model. First the original data base of the general model is updated by calculating the level of the structural macro variables: gross domestic product, market capitalization and good governance. ${ }^{23}$ Tables 4 and 5 show the Logit and Probit Estimates of Equation (2) with the new data base. The results confirm the robustness of three main determinants: the institutional, economic and law factors. The market factor becomes significant, showing a positive relationship between the level of consolidation and the market oriented structure.

Secondly, since we are studying a policymaker's general trend in reforming supervision, rather than a specific trend in consolidation, we may wonder if there is some kind of "bandwagon effect" at work among the policymakers: the policymaker in a given country implements a reform of the supervisory framework, because other countries are doing the same thing, in other words, because it is becoming fashionable. To test the bandwagon effect, we construct a new variable: for each country, we take the year in which the last reform in supervision was implemented (Yeareform). The hypothesis is that, with a bandwagon effect, recent reforms are likely to correspond to higher level of consolidation. ${ }^{24}$ Tables 6 and 7 show that the new variable is not significant. This finding seems to confirm an activism on the part of the policymakers in reforming the supervisory architecture, rather than an attempt at mimicking the establishment of a single regulatory authority. So, while there might be some form of demonstration effect-reforming because others are reforming — it is certainly not clear from

\footnotetext{
${ }^{22}$ This finding is consistent with the so-called small open economy-argument for unification of the supervisory functions. The argument was first developed by Taylor and Fleming (1999) in their analysis of the Scandinavian experience with supervisory integration in the late 1980s and early 1990s. The argument has later been used by other countries to justify the establishment of a unified supervision (for examples, see contributions in Masciandaro, 2005b).

${ }^{23}$ Masciandaro (2005a) used for each of the three variables the mean of four periods in time: 1996, 1998, 2000, 2002. Here we compute the mean by adding a fifth value: 2004 .

${ }^{24}$ We acknowledge that the yeareform variable is a fairly imperfect proxy for a possible bandwagon effect. The best way to calculate this effect would be the construction of an index of the change in each country in the level of supervision consolidation before and after the last reform.
} 
the above finding that the model of complete integration is being copied because it seems fashionable.

The third step addresses the question as to which type of policymaker is in action. To take into account the predictions of both the HHV and the GHV, we have to identify new indicators, given that, under this perspective, the above "market oriented versus bank oriented" variable alone is not sufficient to discriminate between the two views.

The HHV policymaker, in order to increase the efficiency in resource allocation, will address the two most striking financial sector phenomena: the formation of conglomerates and securitization of financial products. However, the role of market trends in influencing the policymaker's decisions is not unequivocal, given that-as we highlighted above-the optimal model of supervision is still to be discovered, and ex-ante a more consolidated supervisory setting can produce either advantages or disadvantages. Therefore, given the market structure, the expected sign of a relationship between the degree of supervision concentration and a proxy of the new financial trends is undetermined-i.e., can be positive or negative-and remains an empirical question. At the same time, the HHV policymaker is by definition immune to any risks of capture.

The GHV policymaker will be sensitive to the preferences of the market participants, irrespective of the actual trends in the financial markets. As we already noted, the demand of the financial industry for more consolidated supervision can hide a risk of capture. Provided that the market participants like a unified supervisory model, and given the market structure, the expected sign of a relationship between the degree of supervision concentration and a proxy of the capture risk is positive.

Thus, the predictions of the theory regarding the two types of policymakers are different, although a degree of ambiguity cannot be eliminated. Given the policymakers’ opposite profiles, we can first test the effect of an indicator of market trends: the conglomeration effect. The relationship between the supervisory unification and the conglomeration effect (Cong) is more likely to be significant if the policymaker is a HHV type. Secondly, we can test the consequences of a proxy of the capture risk: the degree of consolidation in the financial industry. The relationship between supervisory unification and the degree of concentration of the financial system (Conc) is more likely to be significant if the policymaker is a GHV type. In addition, provided that the market participants prefer a unified supervisory model, the expected sign of the relationship is positive. That the two measures of the market factor are different, at least in our sample, is confirmed by their low positive correlation coefficient $(0.0731) .{ }^{25}$ Due to limited data availability on these two variables, the size of the original country sample is reduced from 88 countries to 80 (concentration effect) and 51 countries (conglomeration effect), respectively.

The results are reported in Tables 8-11. The first two tables (8 and 9) show that the conglomeration effect is not significant. In addition, the overall specification looses significance. In contrast, the results in Tables 10 and 11 signal that the concentration effect is

${ }^{25}$ The correlation matrix for the market factor variables is in Table 1B. 
always positive and significant. Furthermore, the relevance of the central bank factor and the law factor are confirmed in this specification. A tentative conclusion from these regressions is that the behavior of policymakers is more consistent with the GHV, presuming a market preference toward supervisory consolidation. More research is certainly needed to arrive at robust conclusions. This could be achieved by identifying better proxies for the market features that are considered relevant in the politicians’ decision-making process.

\section{CASE Study: The MARKet VieW IN ITALY}

Information on the views of the market participants regarding the desirable supervisory architecture and its governance structure is not generally and systematically available. Thus far, researchers have to rely more on anecdotal evidence as indicated earlier (Section II). In this section we will analyse the market view on supervision architecture and regulatory governance in the case of Italy. The analysis is based on a survey conducted among Italian financial industry CEOs regarding the supervisory structure and its governance. As such, it is one of the first attempts to map the views, preferences and beliefs of the sector in a systematic way, and can provide us with a number of additional insights into the dynamics of the evolving debate regarding supervisory structures and their governance.

The Italian situation is particularly interesting, with a bank-based financial system, which has gone through a rapid consolidation in recent years and which is governed by a highly decentralized supervisory model, with five authorities. This model was confirmed by the Italian Parliament in December 2005, but in 2006 the government started discussing a reform aimed at introducing a twin peak regime and revisiting the governance rules. ${ }^{26}$

Thus, we are observing a consolidation process in the markets which will perhaps be accompanied by a consolidation in the supervisory architecture. We wonder if in a more concentrated financial industry the market participants have clear preferences on the level of the supervisory consolidation and on the degree of independence and accountability of the supervisors. The identification of the market view can be useful to analyze the choices of the policymakers, in order to test the chain between the financial structure, the market view and the political preferences.

\section{A. Italy's Financial System Structure}

The Italian financial industry is a typical bank-based system. We acknowledge that often an arbitrary judgement is made to decide whether a country's financial industry is bank-based or market-based. Among the many indicators of the financial structure that have been proposed in the literature, ${ }^{27}$ we use the ratio of stock market capitalization to GDP. While this measure is intuitively simple and appealing, it remains an imperfect benchmark. However this ratio is sufficient to show that Italy still has underdeveloped securities markets. In the overall country

\footnotetext{
${ }^{26}$ The twin peak model was first discussed by Taylor (1995). The model groups supervision of market behavior of all segments of the financial system in one peak, and conduct of business supervision in another. Thus far the model has only been adopted in Australia and the Netherlands.

${ }^{27}$ See among others Beck and others (1999) and Levine (2002).
} 
sample, Italy ranks 30th of 88 (Figure 1), and among the 24 advanced OECD countries, Italy ranks 16th (Figure 2). The Italian stock market is still smaller than that of the other advanced countries, and firms-particularly small and medium sized enterprises-have to depend heavily on

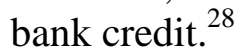

Looking at the country figures alone, banking sector assets accounted for 66.5 percent of the financial system's total assets at end-June 2005. In addition, banks control a substantial share of the asset management industry - the second most important class of financial institutions with 16 percent of total assets - and the insurance sector, the third class with 12 percent. $^{29}$ The pervasive role of the banks is also reflected in the growing concern of the central bank, which drew attention to the need to ensure that asset management companies were independent of the banking and insurance groups which control them and distribute their products. ${ }^{30}$

The degree of concentration of the banking industry has been increasing in recent years. Looking at the total value of deposits held by the five major banks, Italy ranks 64 out of 80 in the country sample (Figure 3 ), and $17^{\text {th }}$ among the 21 OECD countries (Figure 4). However, the number of banks declined from 970 in 1995 to 787 in 2004, ${ }^{31}$ the six largest banks represent 55 percent of total assets at end-2004. ${ }^{32}$ In 2006 the first and third largest banks merged, building up the biggest Italian bank: Intesa SanPaolo. The consolidation process is likely to continue: in February 2007 the Governor of the Banca d' Italia claimed that "there is still room for mergers and acquisitions able to create synergies."33

\section{B. Supervisory Framework}

The supervisory framework is a multi-authority model, built around five institutions. The central bank (Banca d'Italia) is the supervisor of the banking system and, with a view to preserving financial stability, is also responsible for supervising the asset management industry, as well as other relevant financial markets, such as wholesale markets for government securities and interbank markets. Furthermore-until the promulgation of law No. 262 of December 2005 - the central bank was the main authority in charge of enforcing the antitrust law. The central bank was assigned at least two goals: maintaining financial stability and enforcing the antitrust law. The Italian Companies and Stock Exchange Commission (CONSOB) regulates and supervises the Italian securities markets, while the insurance market is supervised by the Insurance Authority (ISVAP). Pension Funds are supervised by the Pension Fund Authority (COVIP). Finally, the Italian Foreign Exchange Office (UIC) is responsible for anti-money laundering and combating terrorist financing. ${ }^{34}$

\footnotetext{
${ }^{28}$ Draghi (2006b), Cardia (2006).

${ }^{29}$ International Monetary Fund (2006).

${ }^{30}$ Draghi (2007).

${ }^{31}$ European Central Bank (2005).

32 International Monetary Fund (2006).

33 Draghi (2007).

${ }^{34}$ International Monetary Fund (2006).
} 
From a theoretical point of view, the Italian regime represents a striking example of the socalled central bank fragmentation effect. ${ }^{35}$ The number of supervisors is directly related to the central bank involvement is supervision itself, reducing the degree of supervisory consolidation. The Italian Parliament, notwithstanding a declaration in favor of supervision by objectives confirmed the multi-authority regime with the abovementioned law No. 262 of December 2005 (New Law on Savings). The same law was designed to reform the governance of the central bank in a number of crucial areas. The law moved the responsibility for regulating anticompetitive behaviour from the central bank to the Antitrust Authority, with shared responsibilities of the two institutions for bank mergers and acquisitions. The law defined five principles-reaffirmation of central bank autonomy, transfer of central bank ownership to public entities, enhanced collegiality, increased reporting requirements, changes to the mandate of the Governor and the other members of the Directorate-with key provisions to be spelled out in the amendments of the central bank statute. ${ }^{36}$ The role of a government committee-The InterMinisterial Committee on Credit and Savings-in supervision makes it difficult to evaluate the real degree of central bank independence in the supervisory area. ${ }^{37}$

In February 2006 the centre-left government proposed a twin-peak supervisory model, or supervision by objectives. ${ }^{38}$ The twin peak model states that all intermediaries and markets be supervised by two authorities, with each single supervisor being responsible for one goal of regulation. The Banca d'Italia would be in charge of financial stability, while CONSOB would be responsible for transparency and conduct of business. Both agencies supported the view that supervision by objectives is necessary. ${ }^{39}$ As part of the reforms, the Inter-Ministerial Committee on Credit and Savings would be eliminated and replaced by a Financial Stability Committee, with three members: the Minister of Treasury (Chairperson), the Governor of the Banca d'Italia, and the President of CONSOB. The Financial Stability Committee would promote the exchange of information, the coordination between the two supervisory agencies, as well as the cooperation between national and international supervisors. Finally, the government proposal defined common rules on the accountability of the two agencies towards the Parliament and its Commissions.

\section{The Market View: The 2006 Survey}

In October-November 2006 a survey, prepared by the authors of this paper, was carried out by the Asset Management Industry (AMI) Association ${ }^{40}$ amongst 230 CEOs ${ }^{41}$ of the AMI firms. Italy currently has 171 AMI firms; ${ }^{42}$ their shareholders are Italian banks (82 percent), Italian non bank financial firms (12 percent ), and foreign financial and banking institutions (6 percent ). The AMI managers are highly representative of the Italian financial community. As noted

\footnotetext{
${ }^{35}$ Masciandaro (2006).

${ }^{36}$ International Monetary Fund (2006), Draghi (2006a).

${ }^{37}$ International Monetary Fund (2006).

${ }^{38}$ Di Giorgio and Di Noia (2007).

${ }^{39}$ Cardia (2005), Draghi (2006a).

40 Assogestioni.

41 “Amministratore delegato" or "Direttore generale.”

42167 Società di Gestione del Risparmio (SGR), 3 Fondi Pensione, 1 Società di Intermediazione Mobiliare (SIM).
} 
above, the asset management industry is the second largest segment of the financial sector, but more importantly, the AMI firms are mainly controlled by the domestic banks.

The answers to the questionnaires (68 respondents, 30 percent of the overall CEO population) offer an original picture of the market view on the key features of the supervisory architecture. In addition to the aim of increasing our understanding of the market view, specific goals of the survey included the identification of the market preferences on the actual and optimal level of key features of the supervisory setting (efficiency, neutrality, staff saving, responsibility) and governance (independence and accountability), as well as the market's views on the political feasibility of their reform.

\section{Present structure}

The first part of the questionnaire surveys the views on the present regime (see Appendix II). Questions 1-8 inquire about the respondents' views on the general features of the supervisory architecture such as the risks of supervisory inefficiency, lack of neutrality, staff surplus, and low responsibility due to the multitude of agencies. Of the respondents, 80 percent estimated that the risk of supervisory inefficiency is high (more than 50 percent) in the present institutional setting. The risk of lack of regulatory neutrality is considered high by 75 percent of the respondents. For 84 percent of the managers, the staff surplus risk is high, while 59 percent of them think that the risk of low responsibility is high. Thus, it appears that the market's appreciation of the overall efficiency of the multi-authority system is low. This view is confirmed by the fact that only 40 percent of the respondents consider the current regime as effective.

\section{Governance of the present structure}

Questions 9-14 deal with views on the governance-independence and accountability-of the two main supervisory authorities: Banca d'Italia and CONSOB. The questions start from the assumption that the governance framework has to be designed in such a way that management of the agencies is free from any form of "capture". The risks of supervisory capture can be classified in three categories: "political capture," "industry capture,” and "self-interest capture."43 Thus, independence from politicians (political independence) and the supervised industry (industry independence) can be considered good practice. ${ }^{44}$ Finally, there is always the risk that a supervisor pursues his/her self interest, which may not be consistent with the social welfare. Hence, there must be transparent reporting procedures on the supervisor's activities, as well as rules on staff integrity, to avoid self bureaucrat capture. Accountability and transparency provide the society with assurances that supervision is not manipulated. ${ }^{45}$

For 45 percent of the Italian financial CEOs, political independence of the Banca d' Italia is high (more than 50 percent), while almost the same percentage of respondents (43 percent) also consider industry independence high. In contrast, only 9 percent of respondents think

\footnotetext{
${ }^{43}$ See Masciandaro, Quintyn and Taylor (2008).

${ }^{44}$ Quintyn and Taylor (2003 and 2007), and Hüpkes, Quintyn and Taylor (2005).

${ }^{45}$ Quintyn and Taylor (2003).
} 
accountability is high. The CONSOB is highly politically independent and industry independent-respectively according to 27 percent and 46 percent of the responders. The level of accountability of CONSOB is considered high by only 8 percent.

\section{Preferred supervisory model}

The second part of the questionnaire deals with views on reforms. The aim of questions 15-28 is to discern if there exists an ideal supervisory setting in the minds of the market participants. The shortcomings of the multi-authority model become evident when analyzing the market preferences with regard to a possible supervision consolidation. In the eyes of the respondents, a reform of the supervisory setting should produce a high (more than 50 percent) reduction in the various sources of inefficiencies. Among the respondents, 36 percent look for a significant reduction in the risk of supervisory inefficiency. The need for a reduction in the risk for a lack of regulatory neutrality is considered high for 47 percent of the respondents. In 45 percent of the cases, the managers think that the risk for a staff surplus should be diminished, and a similar share of respondents favor a reduction in the risk of low responsibility.

While an overall reform is urgent for 79 percent of the respondents, 49 percent of them express a preference for the twin peak model, while the other 51 percent are in favor of a single supervisor. The survey does not document any particular "home bias" preference: exactly 50 percent of the CEOs think that a national supervisor is better (as opposed to a supervisor at the European level), and 60 percent prefer national accountability procedures. Regarding the optimal governance rules for supervisors, the financial professionals are in favor of more political independence (74 percent), more industry independence (72 percent), but also more accountability (90 percent). Among the respondents, 54 percent is a favor or mixed financing rule-a combination of public funds and fees from the supervised intermediaries. What is clear from this survey is that the Italian market view expresses a preference for supervisory consolidation.

\section{Belief in the feasibility of the reforms}

The final set of questions (29-42) seeks to clarify the market beliefs in the feasibility of a reform. The purpose is evaluate the alignment between market preferences and the expected government choice. In general, implementing supervisory reforms is seen as a sign of progress, and respondents see a relatively high probability (more than 50 percent) that a reform will indeed lead to a reduction in the different sources of inefficiencies currently experienced. Among the respondents 68 percent consider a reduction of the risk for supervisory inefficiency likely. A reduction in the risk of a lack of regulatory neutrality is estimated as likely by 65 percent of the respondents. 45 percent of the managers think that it will also lead to a reduction in the staff surplus risk, and 50 percent of them claim that the risk for low responsibility will be reduced. The financial CEOs think that the politicians prefer to establish accountability rules rather than independence procedures. In fact a reform of the supervisory governance is likely to produce higher political independence (41 percent), higher industry independence (47 percent), but mainly higher accountability (57 percent). 
However, 86 percent of the respondents think that the probability of a supervisory reform by the end of the legislation (2011) is equal or less than 50 percent. The conservativeness of the politicians can be explained in different ways. The government can be in general conservative (28 percent), or sensitive to the opposition of the supervisors (26 percent), their unions (57 percent), or their boards of directors (61 percent). Thus, the policymakers' expected behaviour seems to be only weakly consistent with the market wishes. However these answers are not sufficient to disentangle the true nature-HHV or GHV-of the Italian policymaker.

What we can conclude, though, from this experiment is that the operators in the Italian markets are: (i) fairly dissatisfied with the current supervisory model, although they like the degree of political and industry independence of the main regulators-Banca d'Italia and CONSOB-but have some doubts about the low degrees of accountability towards their main stakeholders; (ii) overwhelmingly in favor of a more consolidated model, although there seems to be no outspoken majority for a unified model. The new model should be independent from government and industry, but respondents are more concerned with addressing the current accountability deficit; and (iii) reluctant to think that the expected behaviour and views of the policymakers will be aligned with theirs.

To the extent that parallels can be drawn between these results and worldwide trends, it is worth noting that market participants in Italy are of the view that accountability arrangements are currently weak and should be strengthened significantly, and that they think that politicians are of the same view. This is consistent with worldwide trends, as analyzed in Quintyn, Ramirez and Taylor (2007), and Masciandaro, Quintyn and Taylor (2008), which show that reformed supervisory agencies have stronger accountability arrangements than their predecessors, and in particular than the central banks. So the focus on accountability is certainly growing.

\section{Conclusions}

The current worldwide wave of reforms in supervisory architectures leaves the interested bystander with a great number of questions regarding the true determinants of, and motivations behind, these changes. These questions are all the more justified because the emerging institutional structures are certainly not homogeneous across countries. Trial and error seem to prevail to some extent.

Thus far, academic discussions of the emerging supervisory architectures have been dominated by purely economic views: supervisory structures are being revised because of the blurring boundaries among financial institutions and activities, and the formation of big conglomerates. However, judging from the multiplicity of reform outcomes and politicians' revealed preferences, the natural question which emerges is: to what extent is the changing nature of the markets really being taken into account? And, related to that, to what extent have policymakers been listening to the views of the markets with respect to the desirable supervisory structure?

An answer to these questions requires a political economy approach. Indeed, financial supervisory reform is a political process which involves many stakeholders: the political class, the central bank, the supervised entities, as well as the customers of the financial services. So, the all-encompassing question is: which considerations and views prevail in the end in the decision making process, and to what extent are the decision-makers taking into account the 
views of these different classes of stakeholders when deciding on a reform of the supervisory structures.

This paper tries to answer some of these questions by looking specifically at the impact of the market factor on the decision making process. More specifically, it first develops a model to analyze to what extent policymakers are taking into account the features of the market structure. Secondly, it reports on the results of a survey among Italian market operators on their views on the efficiency of the current supervisory structure, and on the optimal structure-both in terms of architecture and governance.

To answer the first question, the paper starts from two views on the policymaker-the helping hand and the grabbing hand view - to find out empirically how market views are being taken into account. Building upon previous work in this area, we found that the central bank factor, the institutional factor and the law factor, together with the market structure, are significant in the decision-making process. Weak evidence also seems to lean towards the grabbing hand view, but further work is needed.

The survey sheds interesting light on the Italian case—a strong desire for supervisory consolidation with the aim of making the supervisory process more efficient, and a strengthening of governance arrangements through more accountability. The survey also shows that markets believe that the reform views of the politicians are not fully aligned with theirs. However, these findings do not allow us to detect the true nature of the Italian policymakerHHV versus GHV.

While the results of this paper are encouraging, further research is needed. More specifically, the analysis on the determinants of supervisory structures in Masciandaro (2006) and this paper needs to be combined with the research presented in Masciandaro, Quintyn and Taylor (2008) on the determinants of governance arrangements in supervisory agencies. Both shed light on one aspects, but it would be interesting to find out to what extent these two aspectssupervisory architecture and governance arrangements—are two sides of the same coin. Why do politicians in one country allow the central bank to be the single regulator, and why are they inclined in other countries to take supervision out of the central bank and put it in a newly established unified supervisor? Market trends could be one factor in the decision, as this paper shows. However, other elements might be at play as well, such as the desire to have more say in the agency (and thus to take the responsibility away from the independent central bank). Thus, the government's helping or grabbing hand can possibly leave fingerprints all over the new structure. 


\section{REFERENCES}

Abrams, R.K., and M.W. Taylor, 2002, “Assessing the Case for unified sector supervision,” FMG Special Papers No. 134, Financial Markets Group (London: London School of Economics).

Agence France Press, 2006, “Polish ex-Finance Minister named Head of Finance Sector SuperCommission” (September 29).

Alesina, A., and G. Tabellini, 2004, “Bureaucrats or politicians? Part II: Multiple Policy Task,” Discussion Paper No. 2009, Harvard Institute of Economic Research (Massachusetts: Harvard University).

Arnone, M., and A. Gambino, 2007, “Architectures of Supervisory Authorities and Banking Supervision,” in Designing Financial Supervision Institutions: Independence, Accountability and Governance, ed. by Donato Masciandaro and Marc Quintyn (Cheltenham, United Kingdom; Northampton, Massachusetts: Edward Elgar).

Associated Press Newswires, 2006, “The Head of Poland's Central Bank said Tuesday that the bank is suffering the "most extreme" attack on its independence since communism fell in 1989," October 3.

Barth, J., G. Caprio, and R. Levine, 2004, “Bank Regulation and Supervision: What Works Best?” Journal of Financial Intermediation, Vol. 13 (April), pp. 205-48.

Beck, T., A. Demirgüç-Kunt, and R. Levine, 1999, “A New Database on Financial Development and Structure,” Policy Research Working Paper No. 2146 (Washington: World Bank).

Bezuidenhout, Andre, 2004, “The South African Case,” in Aligning Financial Supervisory Structures with Country Needs, ed. by Jeffrey Carmichael, Alexander Fleming, and David Llewellyn (Washington: World Bank).

Briault, Clive, 1999, “The Rationale for a Single National Financial Services Regulator,” Financial Services Authority Occasional Paper No. 2.

Capie, F., 2007, “Some Historical Perspective on Financial Regulation,” in The Structure of Financial Regulation, ed. by Mayes D.G., and G.E. Wood (London and New York: Routledge), pp. 43-65.

Cardia, L., 2005, Annual Report 2004, CONSOB, Rome, March 31 (mimeo).

—_, 2006, Annual Report 2005, CONSOB, Rome, March 31 (mimeo).

Carmichael, Jeffrey, 2002, “Public Sector Governance and the Finance Sector,” in Financial Sector Governance: The Roles of the Public and Private Sectors, ed. by Robert Litan, Michael Pomerleano, and V. Sundararajan (Washington: Brookings Institution Press). 
Čihák, M., and R. Podpiera, 2007, "Experience with Integrated Supervisors: Governance and Quality of Supervision,” in Designing Financial Supervision Institutions: Independence, Accountability and Governance, ed. by Donato Masciandaro and Marc Quintyn (Cheltenham, United Kingdom; Northampton, Massachusetts: Edward Elgar).

Commonwealth of Australia, 1996, "Financial System Inquiry Interim Report,” Wallis Commission (Canberra: Australian Government Publishing Service).

Das, Udaibir, and Marc Quintyn, 2002, "Financial Crisis Prevention and Crisis Management: The Role of Regulatory Governance," in Financial Sector Governance: The Roles of the Public and Private Sectors, ed. by Robert Litan, Michael Pomerleano, and V. Sundararajan (Washington: Brookings Institution Press).

Davis, Howard, 2004, "Integrated Regulation in the United Kingdom and the Lessons for Others," in Aligning Financial Supervisory Structures with Country Needs, ed. by Jeffrey Carmichael, Alexander Fleming, and David Llewellyn (Washington: World Bank).

De Luna Martinez, J., and T.A. Rose, 2003, "International Survey of Integrated Financial Sector Supervision,” Policy Research Working Paper Series No. 3096 (Washington: World Bank)

Dewatripont, Mathias, and Jean Tirole, 1994, The Prudential Regulation of Banks (Cambridge, Massachusetts: The MIT Press).

Di Giorgio, G., and C. Di Noia, 2007, "Financial Supervisors: Alternative Models,” in Designing Financial Supervision Institutions: Independence, Accountability and Governance, Donato Masciandaro and Marc Quintyn, eds. (Cheltenham, United Kingdom; Northampton, Massachusetts: Edward Elgar).

Dow Jones Commodities Service, 2006, “EU “deeply concerned” by new Polish Finci Supervision Law,” September 14.

Draghi, M., 2006a, “Inquiry: Implementation of Law 262/2005,” Sixth Standing Committee, Italian Senate, Rome (September 26) mimeo.

— , 2006b, “World Savings Day,” Association of Italian Savings Banks, Rome (October 31) mimeo.

—_, 2007, "Growth and Stability of the Economy and Financial Markets," AIAF-ASSIOMATIC Forex, Turin (February 3), mimeo.

European Central Bank, 2005, "Consolidation and Diversification in the Euro Area Banking Sector," Monthly Bulletin (May), pp. 79-87. 
Goodhart, C.A.E., 2007, "Financial Supervision from an Historical Perspective: Was the Development of Such Supervision Designed, or Largely Accidental?” in The Structure of Financial Regulation, ed. by Mayes D.G. and G.E. Wood (London and New York: Routledge), pp. 43-65.

Kaufmann, D., A. Kraay, and M. Mastruzzi, 2003, “Governance Matters III: Governance Indicators 1996-2002,” Policy Research Working Paper Series No. 3106 (Washington: World Bank).

International Monetary Fund, 2006, Italy: Financial System Stability Assessment, IMF Country Report No. 6/112 (Washington).

La Porta, R., F. Lopez de Silanes, A. Shleifer, and R.W. Vishny, 1998, “Law and Finance,” Journal of Political Economy, Vol. 106, No. 6, pp. 1113-1155.

— 1997, “Legal determinants of External Finance,” Journal of Finance, Vol. 52, No. 3, pp. 1131-1150.

Levine, R., 2002, “Bank-based or Market-based Financial Systems: Which is Better?” Journal of Financial Intermediation, No. 11, pp. 398-428.

Lutz, S., 2006, “Political Economy Approach to Financial Reform,” in The Political Economy of Financial Market Regulation, ed. by P. Mooslechner, H. Schubert, and B. Weber (Cheltenham, United Kingdom; Northampton, Massachusetts: Edward Elgar), pp. 81-109.

Masciandaro, Donato, 2004, "Unification in Financial Sector Supervision: The Trade Off Between Central Bank and Single Authority,” Journal of Financial Regulation and Compliance, Vol. 12, No. 2, pp. 151-169.

— , 2005a, "E Pluribus Unum? Authorities Design in Financial Supervision: Trends and Determinants,” Open Economies Review, Vol. 17, No. 1, pp. 73-102.

—, (Ed.), 2005b, Handbook of Central Banking and Financial Supervision in Europe (Cheltenham, United Kingdom; Northampton, Massachusetts: Edward Elgar).

— 2006, “Divide et Impera: Financial Supervision Unification and the Central Bank Fragmentation Effect,” European Journal of Political Economy (forthcoming).

—_, and M. Quintyn (Eds.), 2007, Designing Financial Supervision Institutions: Independence, Accountability and Governance (Cheltenham, United Kingdom; Northampton, Massachusetts: Edward Elgar).

—, M. Quintyn, and M. Taylor, 2008, "Financial Stability, Independence and Accountability: Central Banks or Financial Supervisors?” (forthcoming). 
Mwenda, K.K., 2006, “Legal Aspects of Financial Services Regulation and the Concept of a Unified Regulator” (Washington: The International Bank for Reconstruction and Development/The World Bank).

Mooslechner, P., H. Schubert, and B. Weber, 2006, The Political Economy of Financial Market Regulation (Cheltenham, United Kingdom; Northampton, Massachusetts: Edward Elgar).

Pigou, A., 1938, The Economics of Welfare (London: Macmillan \& Co.).

Quintyn, Marc, 2007, “Governance of Financial Supervisors and Its Effects - Some Stocktaking,” SUERF Studies (Vienna), forthcoming.

Quintyn, M., and M. Taylor, 2003, “Regulatory and Supervisory Independence and Financial Stability,” CESifo, Economic Studies, Vol. 49, No. 2, pp. 259-94.

— , 2007, "Robust Regulators and their Political Masters: Independence and Accountability in Theory,” in Designing Financial Supervision Institutions: Independence, Accountability and Governance, ed. by Donato Masciandaro and Marc Quintyn (Cheltenham, United Kingdom; Northampton, Massachusetts: Edward Elgar).

Quintyn, Marc, S. Ramirez, and M. Taylor, 2007, "Fear of Freedom-Politicians and the Independence and Accountability of Financial Sector Supervisors,” in Designing Financial Supervision Institutions: Independence, Accountability and Governance, ed. by Donato Masciandaro and Marc Quintyn (Cheltenham, United Kingdom; Northampton, Massachusetts: Edward Elgar).

Shleifer, A., and R. Vishny, 1998, The Grabbing Hand (Cambridge, Massachusetts: Harvard University Press).

Stigler, G., 1971, “The Theory of Economic Regulation,” Bell Journal of Economics and Management Science, Vol.2, pp. 3-21.

Taylor, Michael, 1995, Twin Peaks: A Regulatory Structure for the New Century (London: Centre for the Study of Financial Innovation).

Taylor, Michael, and Alex Fleming, 1999, “Integrated Financial Supervision. Lessons from Northern European Experience,” Policy Research Working Paper No. 2223 (Washington: World Bank).

Westrup, Jonathan, 2007, “Independence and Accountability: Why Politics Matter, “in Designing Financial Supervision Institutions: Independence, Accountability and Governance, ed. by Donato Masciandaro and Marc Quintyn (Cheltenham, United Kingdom; Northampton, Massachusetts: Edward Elgar). 
Table 1A. Correlation Matrix: General

\begin{tabular}{|c|c|c|c|c|c|c|c|c|c|c|c|}
\hline & Fac & Cbfa & Mvb & Mktc. & Goodg. & Gdp & $\mathrm{Eu}$ & Ocse & Com. & Civil & Latitude \\
\hline Fac & 1.0000 & & & & & & & & & & \\
\hline Cbfa & -0.3332 & 1.0000 & & & & & & & & & \\
\hline Mvb & 0.0986 & 0.0173 & 1.0000 & & & & & & & & \\
\hline Mktc. & 0.2480 & 0.0052 & 0.5043 & 1.0000 & & & & & & & \\
\hline Goodg. & & 0.4529 & -0.0955 & 0.1997 & 0.6142 & 1.0000 & & & & & \\
\hline Gdp & -0.0116 & -0.0137 & 0.2156 & 0.2931 & 0.2675 & 1.0000 & & & & & \\
\hline $\mathrm{Eu}$ & 0.3150 & 0.0083 & -0.0145 & 0.2252 & 0.5719 & 0.0109 & 1.0000 & & & & \\
\hline Ocse & 0.3987 & -0.1424 & 0.3045 & 0.4616 & 0.7491 & 0.3262 & 0.5569 & 1.0000 & & & \\
\hline Com. & -0.0695 & 0.2045 & 0.2928 & 0.2955 & 0.1543 & 0.1732 & -0.1320 & -0.0081 & 1.0000 & & \\
\hline Civil & 0.2598 & -0.2026 & -0.1181 & -0.0121 & 0.1437 & -0.0149 & 0.0613 & 0.1755 & -0.5188 & 1.0000 & \\
\hline Latitude & 0.3218 & -0.0639 & 0.0886 & 0.1975 & 0.4941 & 0.0924 & 0.5492 & 0.5417 & -0.2062 & -0.1529 & 1.0000 \\
\hline
\end{tabular}

Table 1B. Correlation Matrix: Market Factor Variables

\begin{tabular}{lrrrr}
\hline & Mvb & Mcap & Conc & Conglo \\
\hline Mvb & 1.0000 & & & \\
Mcap & 0.4776 & 1.0000 & & \\
Conc & -0.2346 & -0.1953 & 1.0000 & \\
Conglo & -0.0333 & -0.0361 & 0.0731 & 1.0000 \\
\hline
\end{tabular}

Table 1C. Summary Statistics: Market Factor Variables

\begin{tabular}{lrrrrr}
\hline Variable & Obs & Mean & Std. Dev. & \multicolumn{1}{c}{ Min } & \multicolumn{1}{c}{ Max } \\
\hline Mvb & 88 & .25 & .4354942 & 0 & 1 \\
Mcap & 88 & .4020658 & .4601134 & 0 & 2.339196 \\
Conc & 80 & 68.04188 & 19.30137 & 21 & 100 \\
Conglo & 51 & 46.02882 & 38.11922 & 0 & 100 \\
\hline
\end{tabular}


Table 2. Ordered Logit Estimates with the Basic Model

\begin{tabular}{lrrrrrr}
\hline & \multirow{2}{*}{ Ordered logit estimates } & & \multicolumn{4}{c}{ Number of obs $=88$} \\
\cline { 5 - 7 } & & & \multicolumn{4}{c}{ LR chi2(11)=43.15 } \\
\hline Fog likelihood $=-128.11797$ & \multicolumn{4}{c}{ Pseudo R2 $=0.0000$} \\
\hline Cbfa & -.5469927 & .3202533 & -1.71 & $0.088^{*}$ & -1.174678 & .0806923 \\
Gdp & -.0006181 & .0002351 & -2.63 & $0.009 * * *$ & -.0010788 & -.0001573 \\
Oecd & -.0856546 & .808181 & -0.11 & 0.916 & -1.66966 & 1.498351 \\
Mvb & .2726525 & .6227045 & 0.44 & 0.661 & -.9478258 & 1.493131 \\
Mcap & .6775869 & .6378848 & 1.06 & 0.288 & -.5726443 & 1.927818 \\
Ggov & .1887665 & .5255518 & 0.36 & 0.719 & -.8412962 & 1.218829 \\
Eu & .4574519 & .6961968 & 0.66 & 0.511 & -.9070686 & 1.821973 \\
Lat & 1.342584 & 1.788981 & 0.75 & 0.453 & -2.163755 & 4.848923 \\
Len & 1.050421 & .7972013 & 1.32 & 0.188 & -.5120653 & 2.612907 \\
Lfr & 1.447424 & .6550381 & 2.21 & $0.027 * *$ & .1635731 & 2.731275 \\
Lgs & 3.732267 & 1.06465 & 3.51 & $0.000 * * *$ & 1.645591 & 5.818943 \\
\hline
\end{tabular}

Note: $* * *$ indicates statistical significance at 1 percent; $* *$ indicates statistical significance at 5 percent; * indicates statistical significance at 10 percent. 
Table 3. Ordered Probit Estimates with the Basic Model

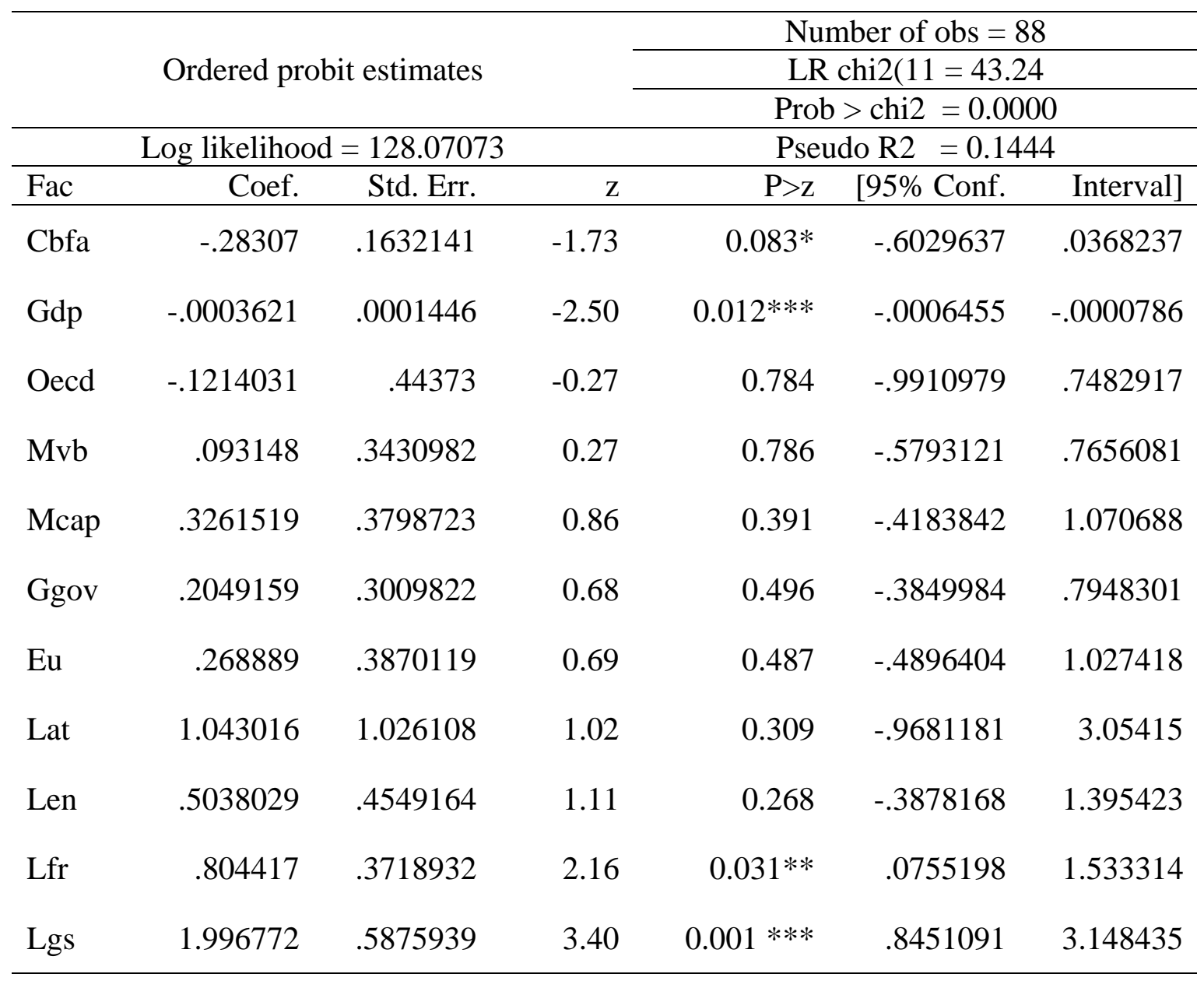

Note: $* * *$ indicates statistical significance at 1 percent; $* *$ indicates statistical significance at 5 percent; * indicates statistical significance at 10 percent. 
Table 4. Ordered Logit Estimates with the Basic Model and the New Data

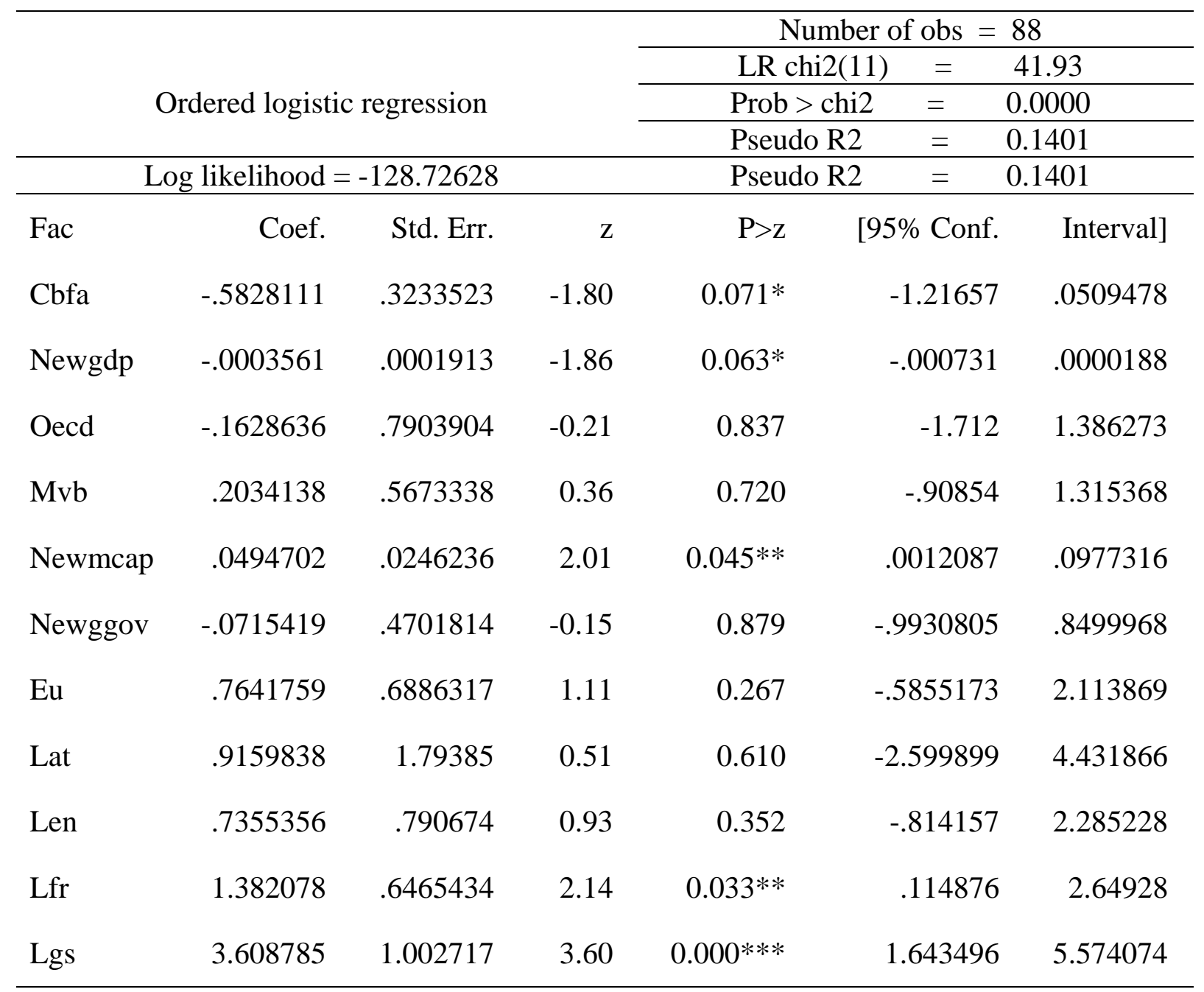

Note: ${ }^{* * *}$ indicates statistical significance at 1 percent; $* *$ indicates statistical significance at 5 percent; * indicates statistical significance at 10 percent. 
Table 5. Ordered Probit Estimates with the Basic Model and New Data

\begin{tabular}{|c|c|c|c|c|c|c|}
\hline \multicolumn{4}{|c|}{ Ordered probitregression } & $\begin{array}{l}\text { LR chi2(11) } \\
\text { Prob > chi2 }\end{array}$ & \multicolumn{2}{|c|}{$\begin{array}{c}=\quad 41.42 \\
=0.0000\end{array}$} \\
\hline \multicolumn{3}{|c|}{ Log likelihood= 128.9813} & & Pseudo R2 & $=0$. & \\
\hline Fac & Coef. & Std. Err. & $\mathrm{z}$ & $\mathrm{P}>\mathrm{Z}$ & [95\% Conf. & Interval] \\
\hline Cbfa & -.296477 & .1631718 & -1.82 & $0.069 *$ & -.6162878 & .0233338 \\
\hline Newgdp & -.000187 & .0000979 & -1.91 & $0.056 * *$ & -.0003789 & 4.89e-06 \\
\hline Oecd & -.1798888 & .4361038 & -0.41 & 0.680 & -1.034637 & .6748589 \\
\hline Mvb & .0537182 & .3198931 & 0.17 & 0.867 & -.5732607 & .6806971 \\
\hline Newmcap & .0254883 & .0146022 & 1.75 & $0.081 *$ & -.0031315 & .0541082 \\
\hline Newggov & .0355907 & .2709747 & 0.13 & 0.896 & -.4955099 & .5666913 \\
\hline $\mathrm{Eu}$ & .4748063 & .3865006 & 1.23 & 0.219 & -.282721 & 1.232334 \\
\hline Lat & .8183801 & 1.027621 & 0.80 & 0.426 & -1.19572 & 2.83248 \\
\hline Len & .366341 & .4563411 & 0.80 & 0.422 & -.5280712 & 1.260753 \\
\hline Lfr & .7951951 & .3693477 & 2.15 & $0.031^{* *}$ & .0712869 & 1.519103 \\
\hline Lgs & 1.962072 & .5699604 & 3.44 & $0.001^{* * *}$ & 8449701 & 3.079174 \\
\hline
\end{tabular}

Note: *** indicates statistical significance at 1 percent; $* *$ indicates statistical significance at 5 percent; * indicates statistical significance at 10 percent. 
Table 6. Ordered Logit Estimates with the Bandwagon Effect

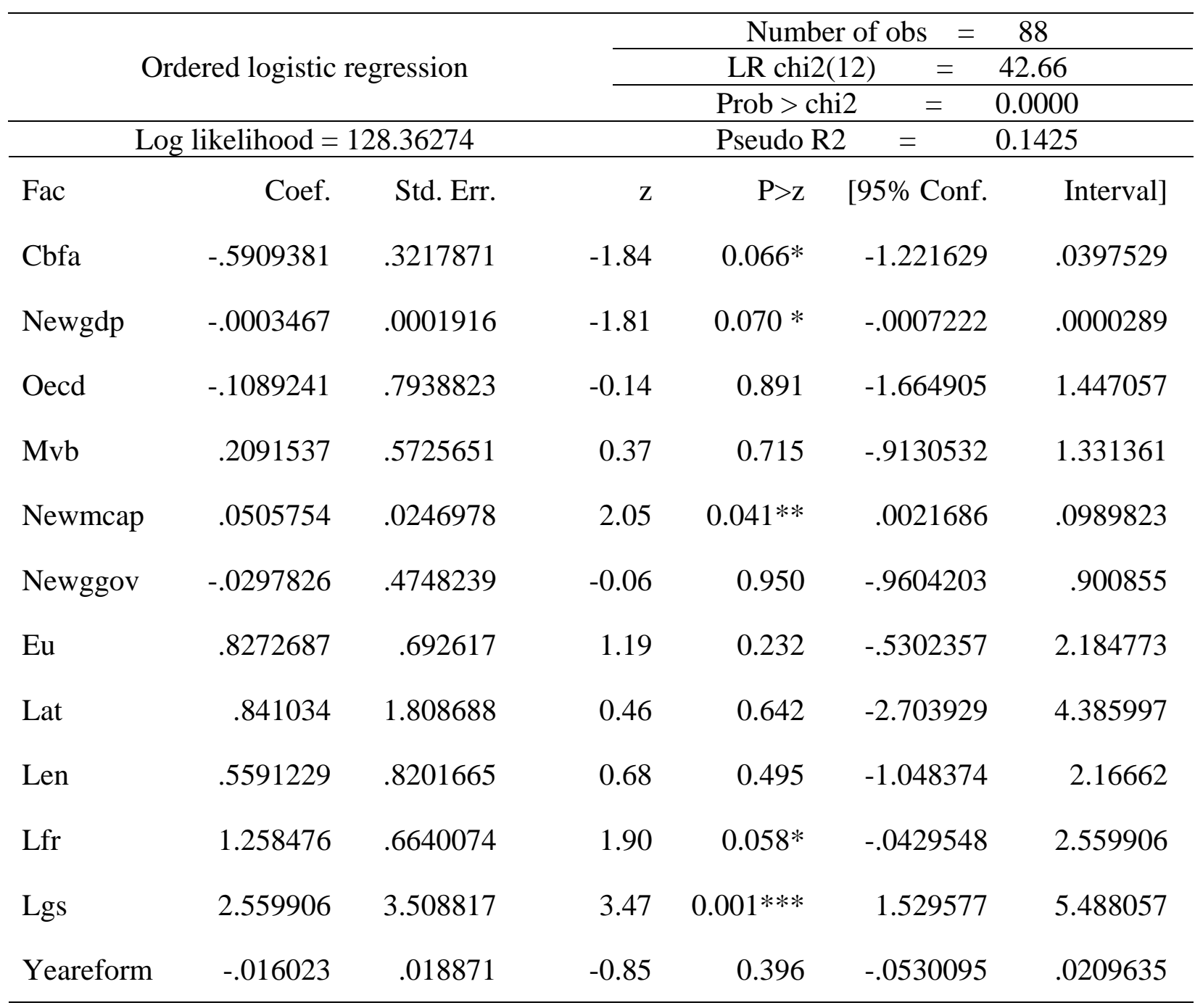

Note: *** indicates statistical significance at 1 percent; $* *$ indicates statistical significance at 5 percent; * indicates statistical significance at 10 percent. 
Table 7. Ordered Probit Estimates with the Bandwagon Effect

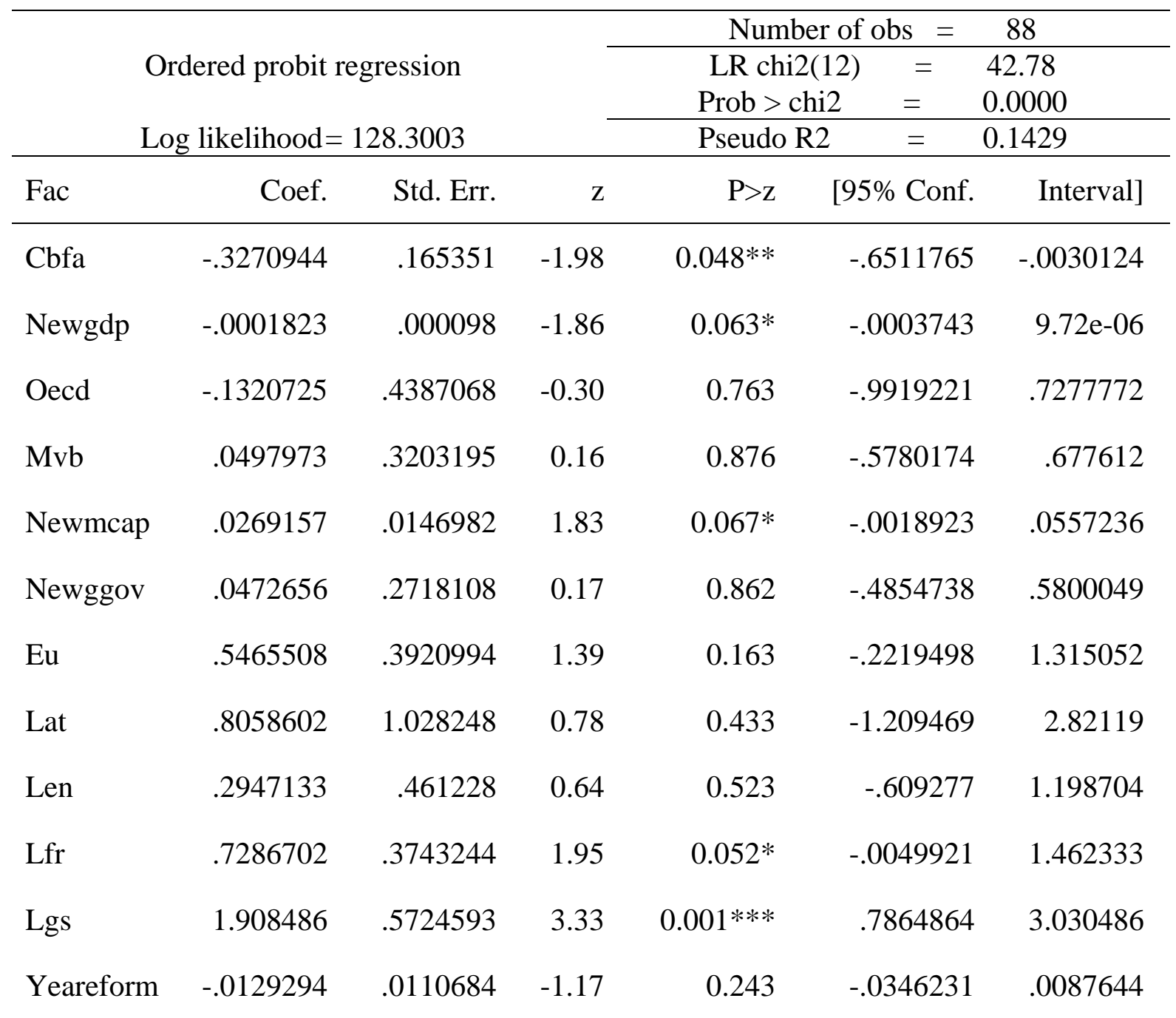

Note: $* * *$ indicates statistical significance at 1 percent; ${ }^{* *}$ indicates statistical significance at 5 percent; * indicates statistical significance at 10 percent. 
Table 8. Ordered Logit Estimates with the Conglomeration Effect

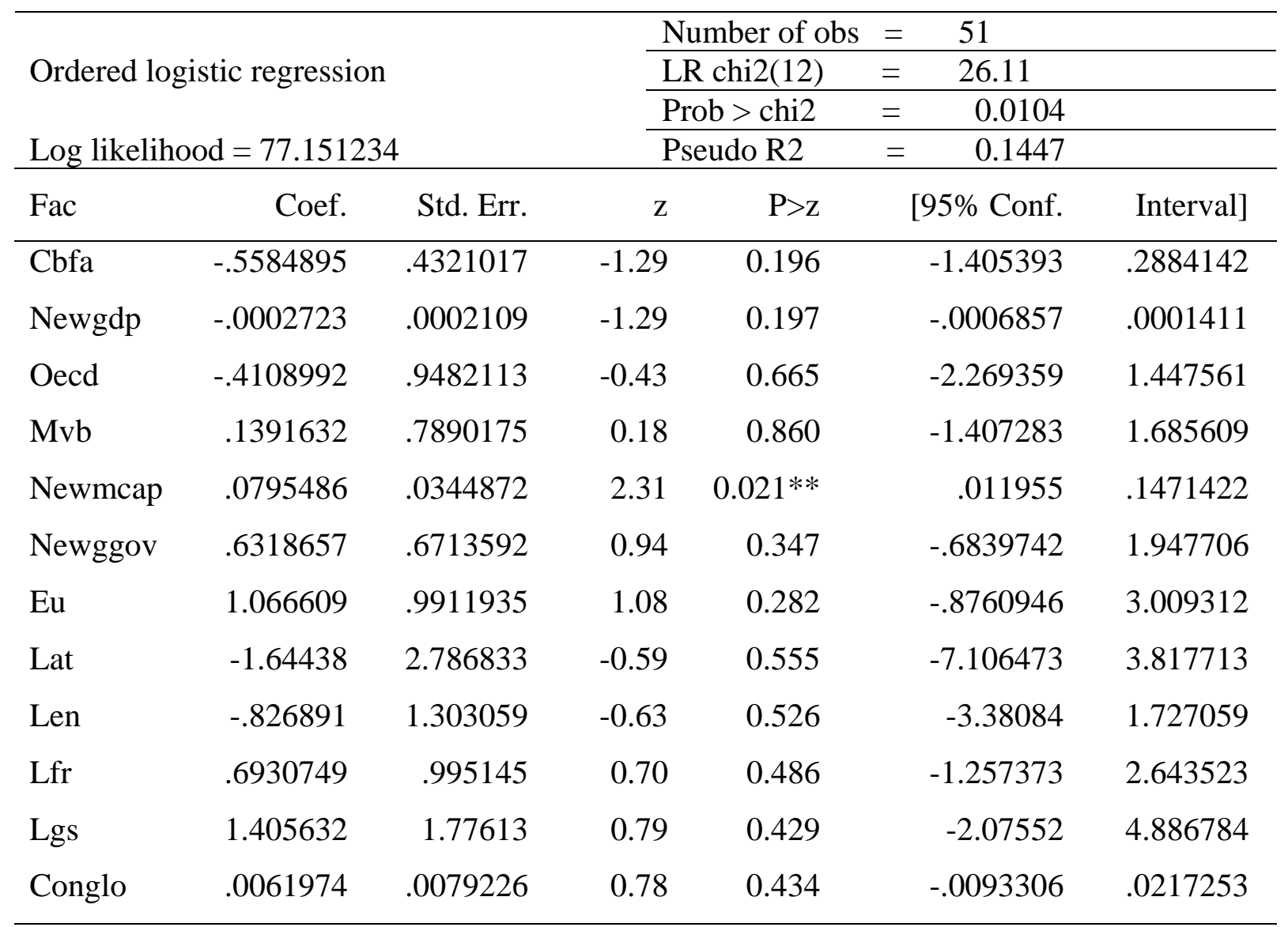

Note: $* * *$ indicates statistical significance at 1 percent; $* *$ indicates statistical significance at 5 percent; * indicates statistical significance at 10 percent. 
Table 9. Ordered Probit Estimates with the Conglomeration Effect

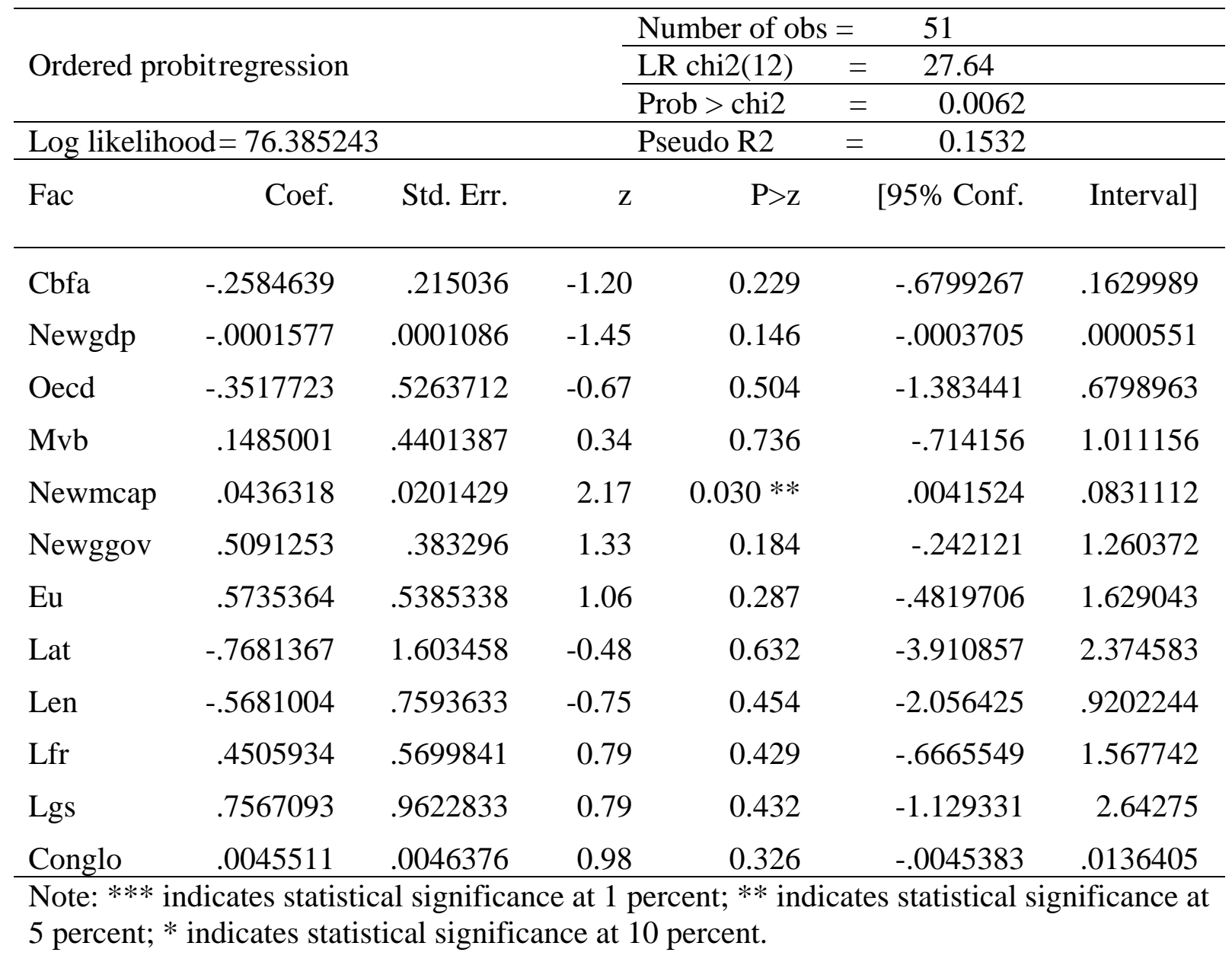


Table 10. Ordered Logit Estimates with the Concentration Effect

\begin{tabular}{|c|c|c|c|c|c|c|c|}
\hline \multirow{3}{*}{\multicolumn{3}{|c|}{ Ordered logistic regression }} & \multicolumn{3}{|c|}{ Number of obs $=$} & \multicolumn{2}{|l|}{80} \\
\hline & & & \multicolumn{2}{|c|}{ LR chi2(12) } & $=$ & \multicolumn{2}{|l|}{54.55} \\
\hline & & & \multicolumn{2}{|c|}{ Prob > chi2 } & $=$ & 0.0000 & \\
\hline \multicolumn{3}{|c|}{ Log likelihood = 109.9207} & \multicolumn{3}{|c|}{ Pseudo R2 } & \multicolumn{2}{|l|}{0.1988} \\
\hline Fac & Coef. & Std. Err. & $\mathrm{z}$ & $\mathrm{P}>\mathrm{Z}$ & & [95\% Conf. & Interval] \\
\hline Cbfa & -1.269573 & .3780443 & -3.36 & $0.001^{* * *}$ & & -2.010526 & -.5286192 \\
\hline Newgdp & -.0002461 & .0001787 & -1.38 & 0.168 & & -.0005964 & - \\
\hline Oecd & -.5715701 & .8203144 & -0.70 & 0.486 & & -2.179357 & 1.036216 \\
\hline Mvb & .7639012 & 6186033 & 1.23 & 0.217 & & -.448539 & 1.976341 \\
\hline Newmkt & .0493506 & .0270567 & 1.82 & $0.068^{*}$ & & -.0036796 & - 1023809 \\
\hline Newggov & .2131225 & .5620199 & 0.38 & 0.705 & & -.8884162 & 1.314661 \\
\hline $\mathrm{Eu}$ & 1.300666 & .7456767 & 1.74 & $0.081^{*}$ & & -.1608337 & 2.762165 \\
\hline Lat & -1.225613 & 2.014232 & -0.61 & 0.543 & & -5.173434 & 2.722208 \\
\hline Len & .204566 & .8697491 & 0.24 & 0.814 & & -1.500111 & 1.909243 \\
\hline Lfr & 1.272444 & 6959135 & 1.83 & $0.067 *$ & & -.0915211 & 2.63641 \\
\hline Lgs & 3.847526 & 1.097419 & 3.51 & $0.000^{* * *}$ & & 1.696623 & 5.998428 \\
\hline Conc & .0268474 & .0130873 & 2.05 & $0.040 * *$ & & .0011967 & 0524981 \\
\hline
\end{tabular}

Note: $* * *$ indicates statistical significance at 1 percent; ** indicates statistical significance at 5 percent; * indicates statistical significance at 10 percent. 
Table 11. Ordered Probit Estimates with Concentration Effect

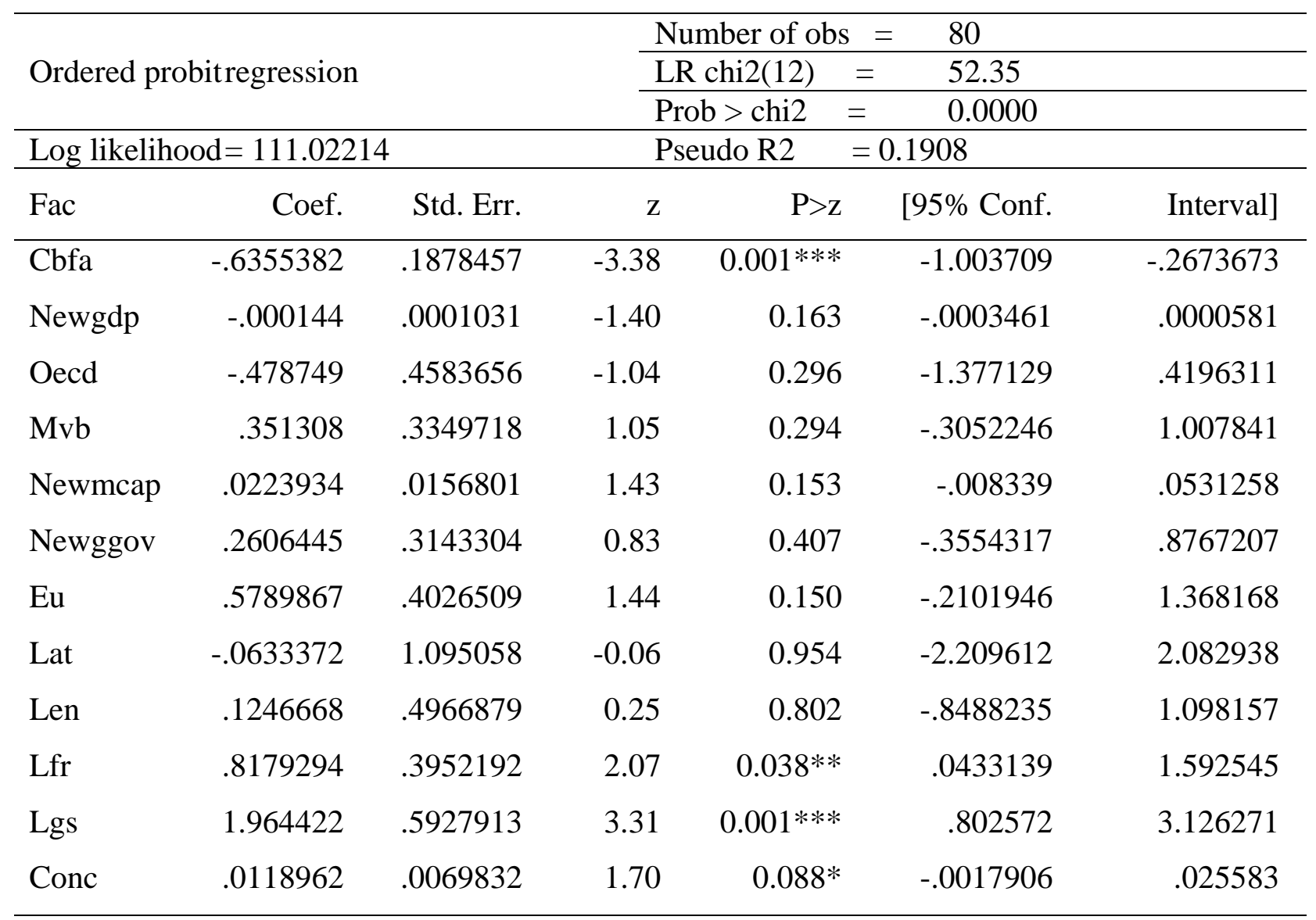

Note: $* * *$ indicates statistical significance at 1 percent; $* *$ indicates statistical significance at 5 percent; * indicates statistical significance at 10 percent. 
Figure 1. MCAP/GDP: Overall Sample

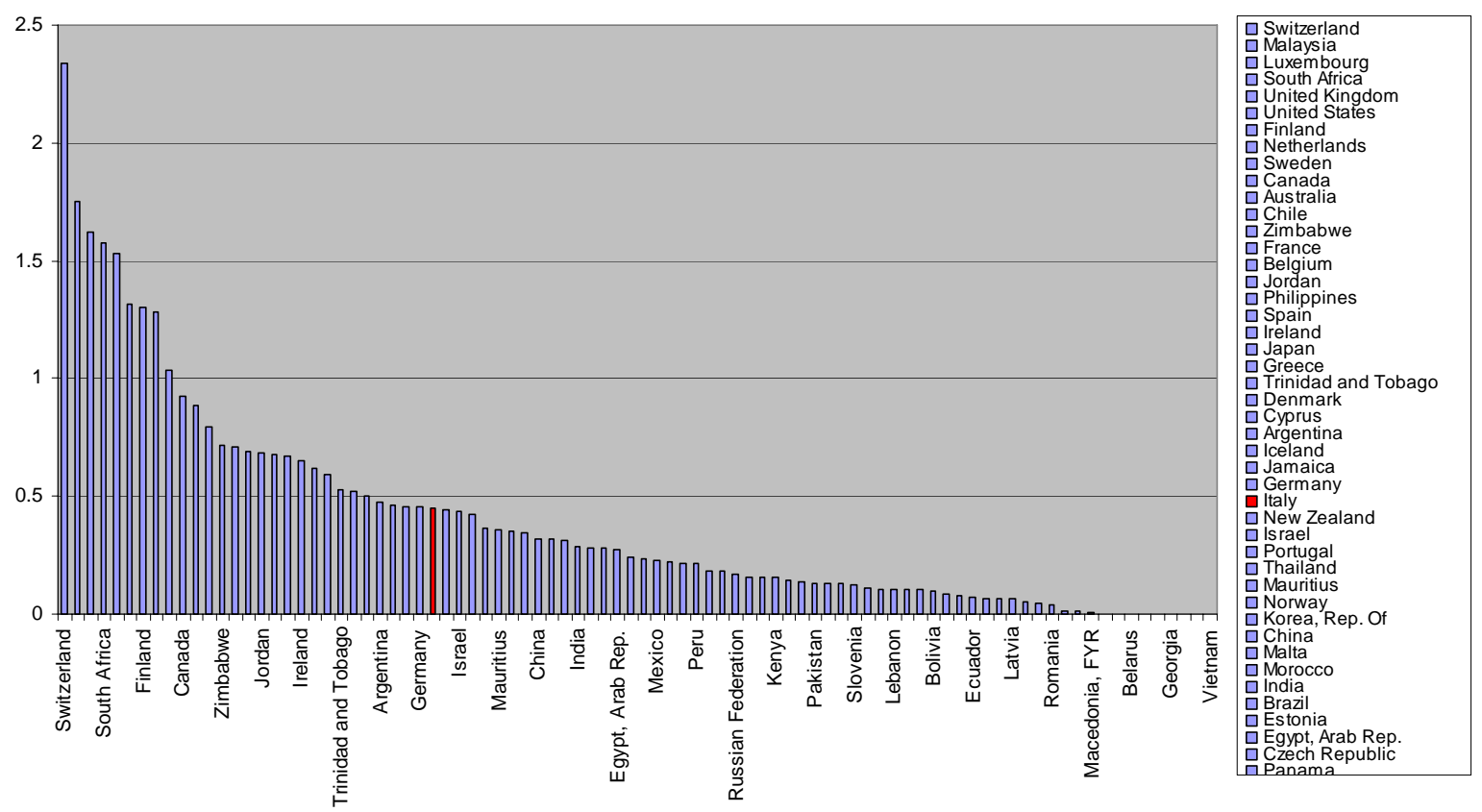

Figure 2. MCAP/GDP:

OECD Countries

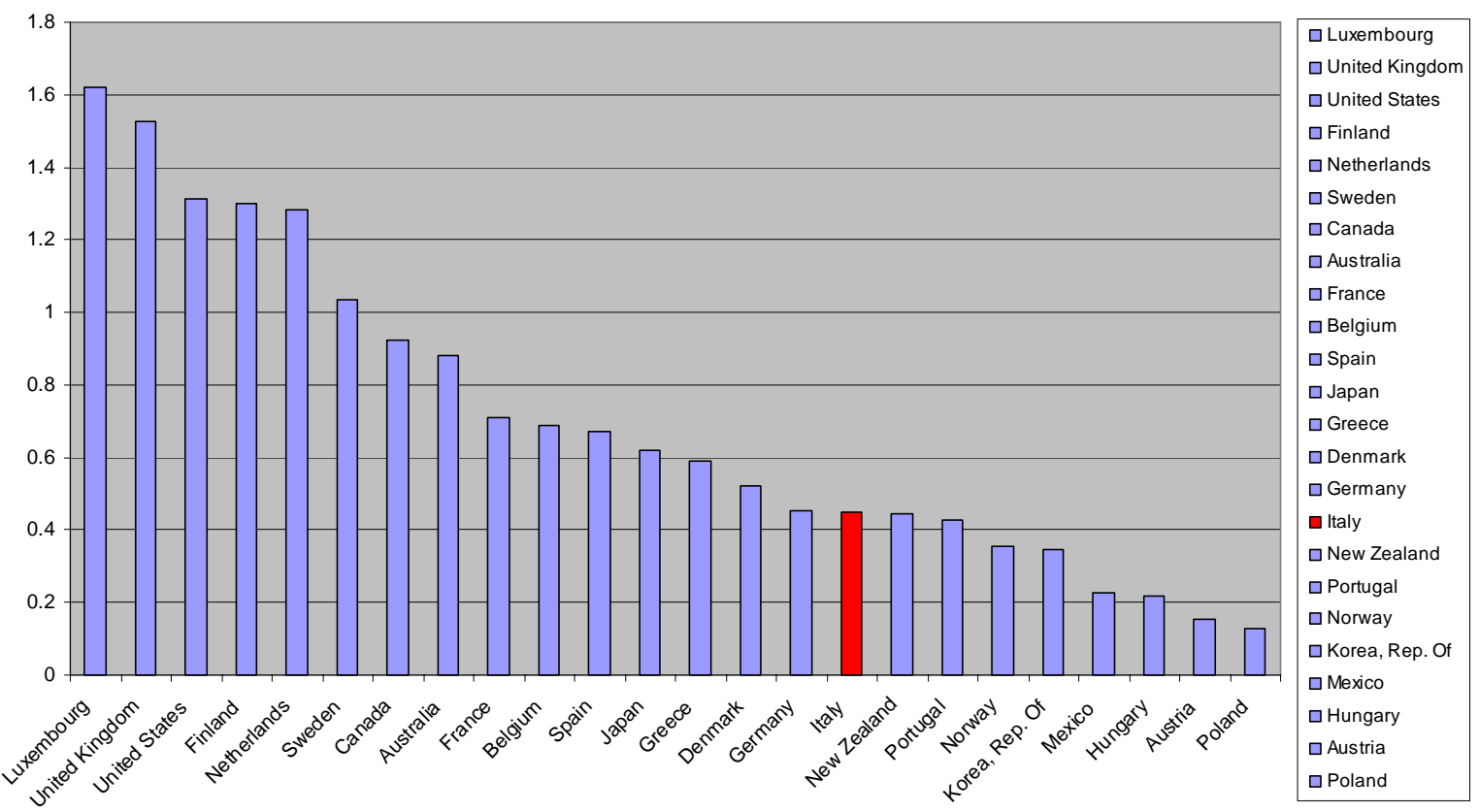


Figure 3. Concentration of Overall Sample

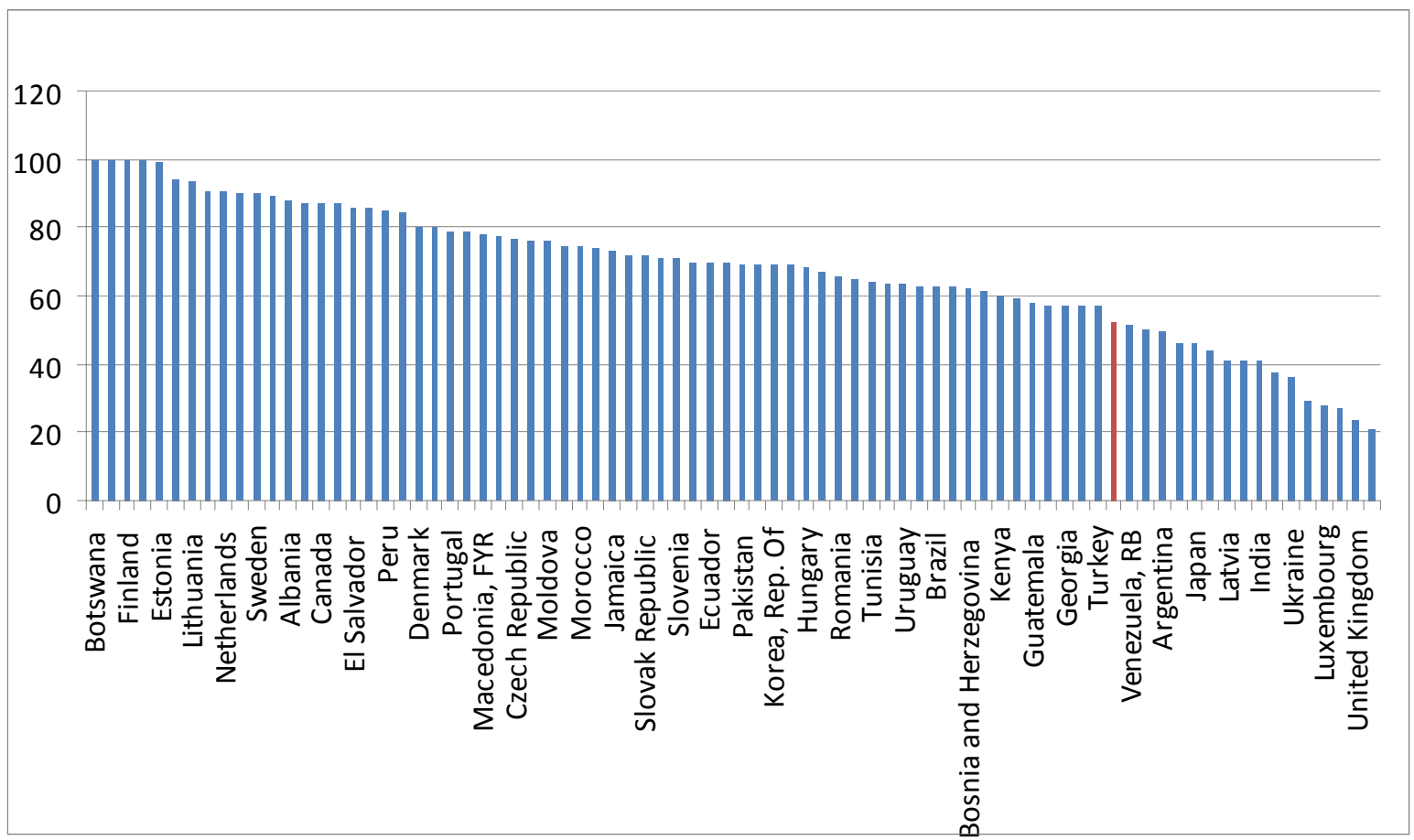

Figure 4. Concentration of OECD Sample

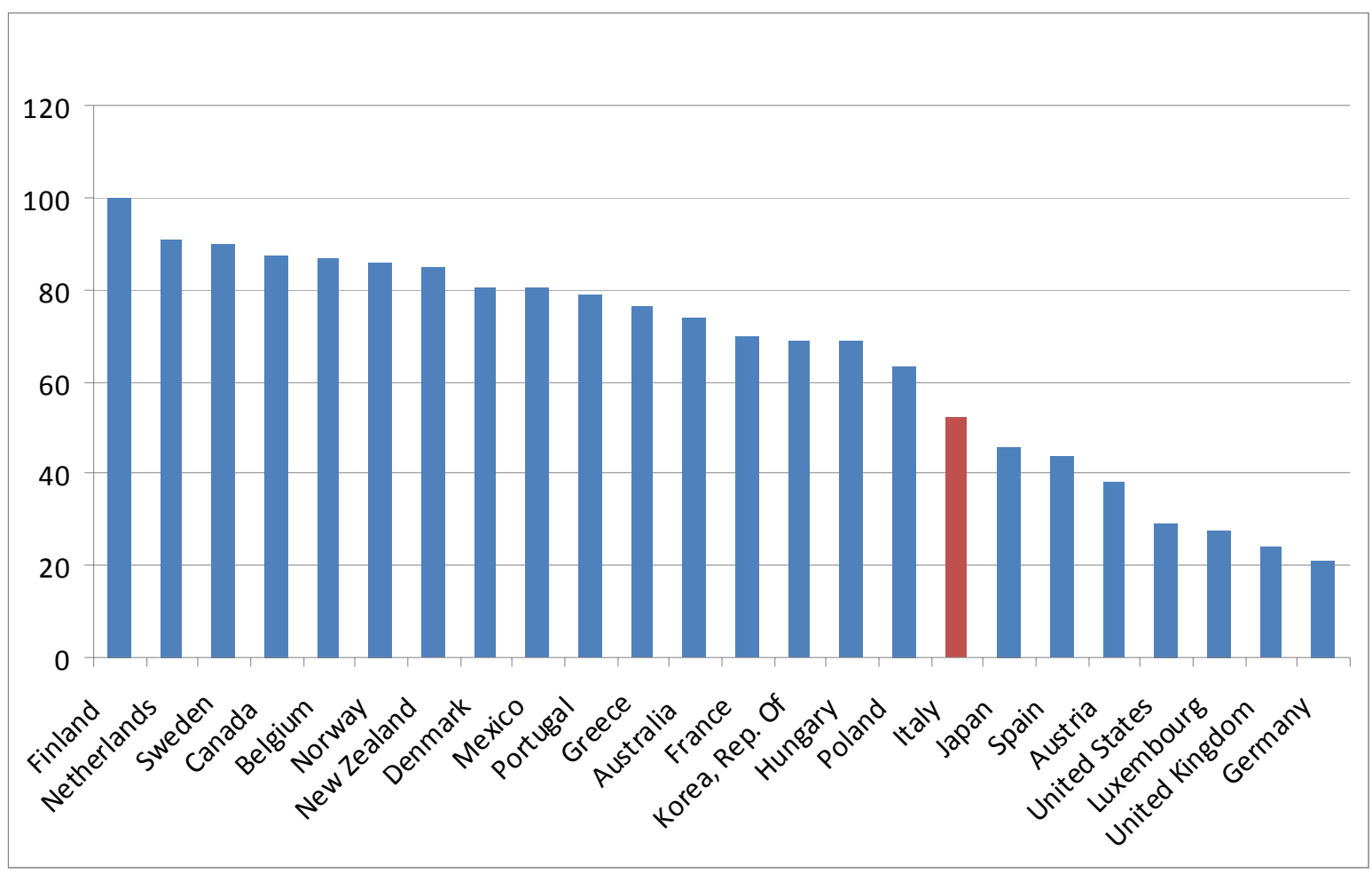




\section{Appendix I: List of Variables}

1. CBFA = variable for the central bank factor. It is the index of involvement of the central bank in supervision (Masciandaro, 2004);

2. GDP = Gross Domestic Product: quantitative variable for the size factor; World Bank, 2003, World Development Indicators. For each variable we calculate the mean of four time values: 1996, 1998, 2000, 2002;

3. OECD = qualitative variable for the size factor. A dummy that signals whether a given country is a member of the OECD or not;

4. MvB = Market vs Bank Index: qualitative variable for the market factor. A dummy that expresses the financial system of a given country, market-based versus bank-based; World Bank, 2003, World Development Indicators. For each variable we calculate the mean of four time values: 1996, 1998, 2000, 2002;

5. MCAP = Market capitalization/GDP: quantitative variable for the market factor. It shows a measure of the securities market size, relative to GDP; World Bank, 2003, World Development Indicators, Stock Markets 5.3. For each variable we calculated the mean of four time values: 1996, 1998, 2000, 2002. Note that the correlation index between the financial regime variable (MvB) and the market capitalization variable (mcap) is high, but their influence on the dependent variable is very low;

6. GGOV = Good Governance: quantitative variable for the political factor. It shows the structural capacity of the government to formulate and implement sound policies. Furthermore the index can represent the control variable for the politics and finance view; The index is built using all the indicators proposed by Kaufmann et al. (2003). They define (public) governance as the exercise of authority through formal and informal traditions and institutions for the common good, thus encompassing: (1) the process of selecting, monitoring and replacing governments; (2) the capacity to formulate and implement sound policies and deliver public services; (3) the respect of citizens and the state for the institutions that govern economic and social interactions among them. Furthermore, for measurement and analysis purposes, these three dimensions of governance can be further unbundled to produce two measurable concepts for each of the dimensions above, for a total of six components: (1) voice and external accountability; (2) political stability and lack of violence; 3) government effectiveness; 4) lack of regulatory burden; 5) rule of law; 6) control of corruption. The authors present a set of estimates of these six dimensions of governance for four time periods: 1996,1998,2000,2002. For every country, therefore, we first calculate the mean of the four time values for each dimension of governance; then we build up an index of global good governance in the period 1996-2002, calculating the mean of the six different dimensions;

7. $\mathbf{E U}$ = binary variable for the geographical factor. It is a dummy that signals whether a given country is European or not;

8. LAT = quantitative variable for the geographical factor. The variable is calculated as the absolute value of the latitude of the country, scaled to take values between 0 and 1; La Porta, Lopez de Silanes, Schleifer, Vishny (1999). On the endowment view, also see Beck, Demirguc-Kunt and Levine (2001);

9-11. LEN LFR, LGS = binary variables for the law factor. They are dummies that indicate the legal root of a given country, representing the control variables for the law and finance view. Beck, Demirguc-Kunt and Levine (2001). There are five legal roots: Anglo-Saxon Law (=Common Law), French, German and Scandinavian Laws (=Civil Laws), Socialist Law (Others); we put together German \& Scandinavian roots, and we skip one root-choosing the Socialist Laws, as the least significant from an economic point of view-to avoid multi-collinearity problems;

12 year reform - year of most recent reform of supervisory architecture;

13 CONG - degree of conglomaration The variable is derived from the database contained in CaprioLevine (2003) and corresponds to their question 2.4. World Bank, 2003, World Development Indicators. For each variable we calculate the mean of four time values: 1996, 1998, 2000, 2002;

14 CONC - degree of concentration The variable is constructed as the percentage of total deposits held by the five largest banks in the country at the end of 2001. The variable is derived from question 2.6.2 of the new database constructed by Caprio-Levine (2003). 
Appendix II: The Questionnaire

Milan, Fall 2006

In a few years, in all the developed countries, the model of financial supervision has been modified. This model has two different configurations: the Single Supervisory Authority (single financial authority-SFA), i.e., supervision for goals (there are three objectivesstability, transparency and fairness, antitrust-each of them is given to a specific authority). Moreover, each country's choice has been influenced by its structural characteristics (market tendencies, real or financial crises).

In Italy, the recent law No. 262 of December 2005 confirmed a hybrid model with a mixed approach (control of the markets which the control for goals has been added to) with six supervisory authorities (Bank of Italy, Consob, Antitrust Authorities, Isavp, Covip, UIC).

The objective of this questionnaire is to identify the market view over financial supervision in Italy. The analysis of the market view is particularly important if we think that the effectiveness of whichever regulatory design depends heavily upon the perception and the judgment of individuals that operate in this regulatory design.

We kindly ask to answer to the following questions trying to express your personal judgment on every single question.

\section{The Actual Regime}

1) An effective supervisory model has to promote the confidence on the system's global stability and, at the same time, its efficiency. The effectiveness level of the actual Italian model of financial supervision is:

Answers (In percent)

\begin{tabular}{|l|r|}
\hline Max = from 75 to 100 & 3 \\
\hline Good = up to 75 & 37 \\
\hline Sufficient $=$ up to 50 & 50 \\
\hline Insufficient $=$ up to 25 & 9 \\
\hline Null = less then 25 & 1 \\
\hline
\end{tabular}

2) Each model of supervision is characterized by compliance. Given the total of working hours of your firm equal to 100, the time devoted to fulfill the duties of the supervisory model (compliance cost of the supervision) is on average:

\begin{tabular}{|l|r|}
\hline From 80 to 100 & 0 \\
\hline From 80 to 60 & 3 \\
\hline From 60 to 40 & 18 \\
\hline From 40 to 20 & 47 \\
\hline From 20 to 10 & 18 \\
\hline From 10 to 0 & 14 \\
\hline
\end{tabular}


3) The multi-authorities model of supervision can produce costs in terms of diseconomies of scale and scope (regulatory inefficiency). The risk of these costs in Italy is:

\begin{tabular}{|l|r|}
\hline Max $=$ from 75 to 100 & 17 \\
\hline High $=$ from 75 to 50 & 63 \\
\hline Medium = from 50 to 25 & 20 \\
\hline Low $=$ from 25 to 10 & 0 \\
\hline Null = from 10 to 0 & 0 \\
\hline
\end{tabular}

4) The multi-authorities model of supervision can create overlapping of controls and/or inequalities in supervision (regulatory no neutrality). The risk of these phenomena in Italy is:

\begin{tabular}{|l|r|}
\hline Max $=$ from 75 to 100 & 15 \\
\hline High =from 75 to 50 & 60 \\
\hline Medium $=$ from 50 to 25 & 22 \\
\hline Low $=$ from 25 to 10 & 3 \\
\hline Null $=$ from 10 to 0 & 0 \\
\hline
\end{tabular}

5) The multi-authorities model of supervision can create a higher number of public employees than necessary (staff surplus). The risk of this phenomenon in Italy is:

\begin{tabular}{|l|r|}
\hline Max $=$ from 75 to 100 & 25 \\
\hline High $=$ from 75 to 50 & 59 \\
\hline Medium $=$ from 50 to 25 & 16 \\
\hline Low $=$ from 25 to 10 & 0 \\
\hline Null $=$ from 10 to 0 & 0 \\
\hline
\end{tabular}

6) The multi -authorities model of supervision can create confusion between the different authorities (institutional deresponsability). The risk of this phenomenon in Italy is:

\begin{tabular}{|l|r|}
\hline Max $=$ from 75 to 100 & 13 \\
\hline High $=$ from 75 to 50 & 46 \\
\hline Medium $=$ from 50 to 25 & 31 \\
\hline Low $=$ from 25 to 10 & 9 \\
\hline Null $=$ from 10 to 0 & 1 \\
\hline
\end{tabular}

7) The supervisory authorities can be more or less sensitive to the compliance costs. In Italy the level of sensibility of authorities is in general:

\begin{tabular}{|l|r|}
\hline Max $=$ from 75 to 100 & 3 \\
\hline High $=$ from 75 to 50 & 4 \\
\hline Medium $=$ from 50 to 25 & 27 \\
\hline Low $=$ from 25 to 10 & 50 \\
\hline Null $=$ from 10 to 0 & 16 \\
\hline
\end{tabular}


8) The model of supervision of a country can represent an incentive/disincentive to foreign entry. The actual Italian supervision model represents:

\begin{tabular}{|l|r|}
\hline A strong incentive & 1 \\
\hline A weak incentive & 7 \\
\hline A strong disincentive & 22 \\
\hline A weak disincentive & 46 \\
\hline A non influential factor & 24 \\
\hline
\end{tabular}

9) The model of supervision has to guarantee the independence from politicians to the control authorities (political capture). In the Italian model of supervision, the degree of independence of the Bank of Italy is:

\begin{tabular}{|l|r|}
\hline Max $=$ from 75 to 100 & 10 \\
\hline High $=$ from 75 to 50 & 35 \\
\hline Medium = from 50 to 25 & 40 \\
\hline Low $=$ from 25 to 10 & 15 \\
\hline Null $=$ from 10 to 0 & 0 \\
\hline
\end{tabular}

10) The model of supervision has to guarantee the independence from politicians to the control authorities (political capture). In the Italian model of supervision, the degree of independence of the Consob is:

\begin{tabular}{|l|r|}
\hline Max $=$ from 75 to 100 & 0 \\
\hline High $=$ from 75 to 50 & 27 \\
\hline Medium = from 50 to 25 & 56 \\
\hline Low $=$ from 25 to 10 & 16 \\
\hline Null $=$ from 10 to 0 & 1 \\
\hline
\end{tabular}

11) The model of supervision has to guarantee the independence from the controlled firms to the control authorities (industry capture). In the Italian model of supervision, the degree of independence of the Bank of Italy is:

\begin{tabular}{|l|r|}
\hline Max $=$ from 75 to 100 & 15 \\
\hline High $=$ from 75 to 50 & 28 \\
\hline Medium = from 50 to 25 & 41 \\
\hline Low $=$ from 25 to 10 & 15 \\
\hline Null $=$ from 10 to 0 & 1 \\
\hline
\end{tabular}


12) The model of supervision has to guarantee the independence from the controlled firms to the control authorities (industry capture). In the Italian model of supervision, the degree of independence of Consob is:

\begin{tabular}{|l|r|}
\hline Max $=$ from 75 to 100 & 12 \\
\hline High $=$ from 75 to 50 & 34 \\
\hline Medium $=$ from 50 to 25 & 46 \\
\hline Low $=$ from 25 to 10 & 7 \\
\hline Null $=$ from 10 to 0 & 1 \\
\hline
\end{tabular}

13) The model of supervision has to be characterized by accountability. In the Italian model of supervision, the level of accountability of the Bank of Italy is:

\begin{tabular}{|l|r|}
\hline Max $=$ from 75 to 100 & 1 \\
\hline High $=$ from 75 to 50 & 8 \\
\hline Medium $=$ from 50 to 25 & 46 \\
\hline Low $=$ from 25 to 10 & 34 \\
\hline Null $=$ from 10 to 0 & 11 \\
\hline
\end{tabular}

14) The model of supervision has to be characterized by accountability. In the Italian model of supervision, the level of accountability of Consob is:

\begin{tabular}{|l|r|}
\hline Max $=$ from 75 to 100 & 0 \\
\hline High $=$ from 75 to 50 & 8 \\
\hline Medium $=$ from 50 to 25 & 49 \\
\hline Low $=$ from 25 to 10 & 32 \\
\hline Null $=$ from 10 to 0 & 11 \\
\hline
\end{tabular}

\section{The Optimal Regime (i.e., A Possible Reform)}

15) What is the level of urgency of reform of the actual model of supervision?

\begin{tabular}{|l|r|}
\hline Max $=$ from 75 to 100 & 20 \\
\hline High $=$ from 75 to 50 & 59 \\
\hline Medium $=$ from 50 to 25 & 20 \\
\hline Low $=$ from 25 to 10 & 1 \\
\hline Null $=$ from 10 to 0 & 0 \\
\hline
\end{tabular}

16) What is the more suitable model of supervision for the Italian context?

\begin{tabular}{|l|r|}
\hline The actual one (6 authorities) & 0 \\
\hline $\begin{array}{l}\text { One according to the function (3 authorities = BI, } \\
\text { Consob, Antitrust) }\end{array}$ & 49 \\
\hline A single supervisor & 51 \\
\hline
\end{tabular}


17) If the adopted model is that with a single supervisory authority, it will be preferable that this authority will coincide with:

\begin{tabular}{|l|r|}
\hline A national authority (The Bank of Italy or Consob) & 50 \\
\hline A European authority of supervision & 50 \\
\hline
\end{tabular}

18) The accountability duties of the national supervisory authorities have to be with respect to:

\begin{tabular}{|l|r|}
\hline To the Ministry of Finance & 10 \\
\hline To the Government & 10 \\
\hline To the Parliament & 36 \\
\hline To the European institutions & 44 \\
\hline
\end{tabular}

19) With respect to the actual situation, the compliance costs (see question 2) should diminish:

\begin{tabular}{|l|r|}
\hline To 100 percent & 0 \\
\hline To 75 percent & 15 \\
\hline To 50 percent & 63 \\
\hline To 25 percent & 19 \\
\hline Not to change & 3 \\
\hline
\end{tabular}

20) With respect to the actual situation, the risks of regulatory inefficiency (see question 3) should diminish:

\begin{tabular}{|l|r|}
\hline To 100 percent & 6 \\
\hline To 75 percent & 30 \\
\hline To 50 percent & 52 \\
\hline To 25 percent & 12 \\
\hline Not to change & 0 \\
\hline
\end{tabular}

21) With respect to the actual situation, the risks of regulatory no neutrality (see question 4) should diminish:

\begin{tabular}{|l|r|}
\hline To 100 percent & 19 \\
\hline To 75 percent & 28 \\
\hline To 50 percent & 37 \\
\hline To 25 percent & 16 \\
\hline Not to change & 0 \\
\hline
\end{tabular}


22) With respect to the actual situation, the risks of the staff surplus (see question 5) should diminish:

\begin{tabular}{|l|r|}
\hline To 100 percent & 14 \\
\hline To 75 percent & 31 \\
\hline To 50 percent & 37 \\
\hline To 25 percent & 15 \\
\hline Not to change & 3 \\
\hline
\end{tabular}

23) With respect to the actual situation, the risks of institutional deresponsability (see question 6) should diminish:

\begin{tabular}{|l|r|}
\hline To 100 percent & 16 \\
\hline To 75 percent & 29 \\
\hline To 50 percent & 31 \\
\hline To 25 percent & 21 \\
\hline Not to change & 3 \\
\hline
\end{tabular}

24) With respect to the actual situation, the sensibility of authorities to the compliance costs should:

\begin{tabular}{|l|r|}
\hline Increase & 87 \\
\hline Remain constant & 10 \\
\hline Diminish & 3 \\
\hline
\end{tabular}

25) With respect to the actual situation, the average level of independence of national supervision authorities with respect to politicians should:

\begin{tabular}{|l|r|}
\hline Increase & 74 \\
\hline Remain constant & 22 \\
\hline Diminish & 4 \\
\hline
\end{tabular}

26) With respect to the actual situation, the average level of independence of national supervision authorities with respect to controlled firms should:

\begin{tabular}{|l|r|}
\hline Increase & 72 \\
\hline Remain constant & 26 \\
\hline Diminish & 2 \\
\hline
\end{tabular}

27) With respect to the actual situation, the average level of accountability of national supervision authorities should:

\begin{tabular}{|l|r|}
\hline Increase & 90 \\
\hline Remain constant & 10 \\
\hline Diminish & 0 \\
\hline
\end{tabular}


28) The financing of the supervision authorities should be done by:

\begin{tabular}{|l|r|}
\hline The public spending & 34 \\
\hline The controlled subjects & 12 \\
\hline The public spending and the controlled subjects & 54 \\
\hline
\end{tabular}

\section{Is a Reform Possible?}

29) What is the probability that the actual model of supervision is reformed before the end of 2006 ?

\begin{tabular}{|l|r|}
\hline Max $=$ from 75 to 100 & 0 \\
\hline High $=$ from 75 to 50 & 2 \\
\hline Medium = from 50 to 25 & 2 \\
\hline Low $=$ from 25 to 10 & 32 \\
\hline Null = from 10 to 0 & 64 \\
\hline
\end{tabular}

30) What is the probability that the actual model of supervision is reformed before the end of the legislation?

\begin{tabular}{|l|r|}
\hline Max $=$ from 75 to 100 & 2 \\
\hline High $=$ from 75 to 50 & 12 \\
\hline Medium = from 50 to 25 & 60 \\
\hline Low $=$ from 25 to 10 & 22 \\
\hline Null $=$ from 10 to 0 & 4 \\
\hline
\end{tabular}

31) What is the probability that a reform of the actual model of supervision that reduces the number of authorities will reduce also the costs of supervision (see question 2)?

\begin{tabular}{|l|r|}
\hline Max $=$ from 75 to 100 & 4 \\
\hline High $=$ from 75 to 50 & 39 \\
\hline Medium = from 50 to 25 & 30 \\
\hline Low $=$ from 25 to 10 & 23 \\
\hline Null $=$ from 10 to 0 & 4 \\
\hline
\end{tabular}

32) What is the probability that a reform of the actual model of supervision that reduces the number of authorities will reduce also the risks of regulatory inefficiency (see question 3)?

\begin{tabular}{|l|r|}
\hline Max $=$ from 75 to 100 & 3 \\
\hline High $=$ from 75 to 50 & 65 \\
\hline Medium = from 50 to 25 & 23 \\
\hline Low $=$ from 25 to 10 & 8 \\
\hline Null= from 10 to 0 & 1 \\
\hline
\end{tabular}


33) What is the probability that a reform of the actual model of supervision that reduces the number of authorities will reduce also the risks of regulatory no neutrality (see question 4)?

\begin{tabular}{|l|r|}
\hline Max $=$ from 75 to 100 & 6 \\
\hline High $=$ from 75 to 50 & 58 \\
\hline Medium $=$ from 50 to 25 & 27 \\
\hline Low $=$ from 25 to 10 & 7 \\
\hline Null $=$ from 10 to 0 & 2 \\
\hline
\end{tabular}

34) What is the probability that a reform of the actual model of supervision that reduces the number of authorities will reduce also the risks of authorities' staff surplus (see question 5)?

\begin{tabular}{|l|r|}
\hline Max $=$ from 75 to 100 & 6 \\
\hline High $=$ from 75 to 50 & 39 \\
\hline Medium $=$ from 50 to 25 & 34 \\
\hline Low $=$ from 25 to 10 & 18 \\
\hline Null $=$ from 10 to 0 & 3 \\
\hline
\end{tabular}

35) What is the probability that a reform of the actual model of supervision that reduces the number of authorities will reduce also the risks of institutional deresponsability (see question 6)?

\begin{tabular}{|l|r|}
\hline Max $=$ from 75 to 100 & 1 \\
\hline High $=$ from 75 to 50 & 49 \\
\hline Medium $=$ from 50 to 25 & 39 \\
\hline Low $=$ from 25 to 10 & 8 \\
\hline Null $=$ from 10 to 0 & 3 \\
\hline
\end{tabular}

36) If the model of supervision in Italy is reformed, it is highly probably that the average level of independence of authorities from politicians will:

\begin{tabular}{|l|r|}
\hline Be increased & 41 \\
\hline Remain constant & 55 \\
\hline Be decreased & 4 \\
\hline
\end{tabular}

37) If the model of supervision in Italy is reformed, it is highly probably that the average level of independence of authorities from the controlled subjects will:

\begin{tabular}{|l|r|}
\hline Be increased & 47 \\
\hline Remain constant & 52 \\
\hline Be decreased & 1 \\
\hline
\end{tabular}


38) If the model of supervision in Italy is reformed, it is highly probably that the average level of accountability of authorities will:

\begin{tabular}{|l|r|}
\hline Be increased & 57 \\
\hline Remain constant & 43 \\
\hline Be decreased & 0 \\
\hline
\end{tabular}

39) Politicians are reluctant to change the actual model of supervision because their sensibility to the change of the status quo is:

\begin{tabular}{|l|r|}
\hline Max $=$ from 75 to 100 & 6 \\
\hline High =from 75 to 50 & 22 \\
\hline Medium = from 50 to 25 & 15 \\
\hline Low $=$ from 25 to 10 & 37 \\
\hline Null= from 10 to 0 & 20 \\
\hline
\end{tabular}

40) Politicians are reluctant to change the actual model of supervision because their sensibility to the opposition of the controlled firms is:

\begin{tabular}{|l|r|}
\hline Max $=$ from 75 to 100 & 3 \\
\hline High $=$ from 75 to 50 & 23 \\
\hline Medium $=$ from 50 to 25 & 36 \\
\hline Low $=$ from 25 to 10 & 26 \\
\hline Null $=$ from 10 to 0 & 12 \\
\hline
\end{tabular}

41) Politicians are reluctant to change the actual model of supervision because their sensibility to the opposition of the unions of control authorities' employees is:

\begin{tabular}{|l|r|}
\hline Max $=$ from 75 to 100 & 14 \\
\hline High $=$ from 75 to 50 & 43 \\
\hline Medium $=$ from 50 to 25 & 35 \\
\hline Low $=$ from 25 to 10 & 6 \\
\hline Null $=$ from 10 to 0 & 2 \\
\hline
\end{tabular}

42) Politicians are reluctant to change the actual model of supervision because their sensibility to the opposition of board of directors of control authorities is:

\begin{tabular}{|l|r|}
\hline Max $=$ from 75 to 100 & 3 \\
\hline High $=$ from 75 to 50 & 58 \\
\hline Medium $=$ from 50 to 25 & 30 \\
\hline Low $=$ from 25 to 10 & 6 \\
\hline Null $=$ from 10 to 0 & 3 \\
\hline
\end{tabular}

